\title{
Diastolic heart failure: A review of clinical status and meta- analysis of the accuracy of tissue doppler diagnosis and the efficacy of exercise training therapy
}

\author{
Aref Albakri* \\ St-Marien hospital Bonn Venusberg, Department of internal medicine, Bonn, Germany
}

\begin{abstract}
Several hospital reports have established diastolic heart failure (DHF) accounts for up to a half of all hospitalized heart failure (HF) patients and a significant cause of morbidity, mortality and re-hospitalization. It is a cardiogeriatric syndrome in the setting of a predominant abnormality in diastolic function. By current projections, the prevalence of DHF will increase over the next several decades driven by an ageing population, an increase in comorbidities (hypertension, obesity and diabetes) and advancements in medical therapies for HF. Although leading cardiology societies have published criteria for the diagnosis and treatment of DHF, the syndrome lacks specific treatment guidelines and protocols. Furthermore, there is limited evidence-based support for the current treatment options based on therapies developed and validated for systolic heart failure (SHF), and as a result, their therapeutic efficacy on DHF patients remains unclear. The purpose of this review and meta-analysis is to provide a broad perspective on the clinical status of DHF with a focus on definition, etiology, pathophysiology, diagnosis and clinical management.
\end{abstract}

\section{Introduction}

Heart failure (HF) is the final common pathway of many cardiovascular risk factors and most forms of heart diseases, and the leading reason for hospitalization and mortality among older adults [1-6]. It is a syndrome characterized by cardiac inability to generate adequate output at rest or during exercise while operating at normal or elevated ventricular filling pressure [7]. Traditionally, HF was associated with impaired left ventricular (LV) systolic function (known as systolic heart failure [SHF]). However, $30 \%$ to $40 \%$ of all HF patients present with normal or slightly depressed LV ejection fraction (LVEF), known as diastolic heart failure (DHF). In these patients, diastolic dysfunction is the major contributor, if not the primary etiology of HF [8]. In contrast to SHF, for which knowledge of pathophysiology and therapy has rapidly advanced over the past three decades, research support for DHF is gradually accumulating but somewhat fragmented. The purpose of this review and meta-analysis of diagnosis and treatment is to combine available research findings on DHF to produce a comprehensive understanding of the current diagnosis and management strategies, and a commentary of emerging treatment strategies.

\section{History, definition, epidemiology and prognosis}

\section{History}

The dichotomy of systolic and diastolic dysfunction represents the original classification system of HF. In a recent editorial, Katz and Zile [8] reported the initial classification of HF appeared over eight decades ago by Fishberg [14], who stratified HF into diastolic and systolic dysfunction based on the inadequacy of diastolic filling and systolic ejection respectively. "...those forms of cardiac insufficiency which are due to inadequate diastolic filling of the heart (hypodiastolic failure) [and] the far more common ones in which the heart fills adequately but does not empty to the normal extent (hyposystolic failure)" [9]. Despite sharing similar clinical and hemodynamic features, the diastolic/systolic distinction persisted overtime because of the recognition that they differ in epidemiology, demographics, etiology and pathophysiology. In SHF, patients exhibit eccentric hypertrophy, progressive LV dilatation and abnormal LV systolic parameters whereas in DHF patients exhibit concentric hypertrophy, preserved or reduced LV volumes, concentric remodeling and abnormal diastolic function [10,11]. The size, shape and molecular composition also differ in the two HF phenotypes [8].

\section{Definition}

Diastolic dysfunction: Diastolic function refers to the sequence of inter-related events occurring during diastole (typically known as the process LV filling). It is the portion of cardiac cycle between the closure of aortic valve and the mitral valve. Two major processes regulating diastolic function are ventricular relaxation and cardiac chamber compliance [12]. Ventricular relaxation is a complex energyintensive process characterized by the deactivation of contractile elements and myofibril returning to their original length. In a healthy heart, ventricular relaxation commences with the closure of the aortic and pulmonary valves during mid-systole and continues throughout the first third of diastolic filling. Diastole may be further divided into isovolumetric relaxation phase and filling phase [13]. During the isovolumetric phase there is decoupling of myocardial contractile elements and falling of the intraventricular pressure with little increase in ventricular volume. Once ventricular pressure falls below left atrial (LA) pressure, the mitral and tricuspid valves open and ventricular filling begins.

${ }^{*}$ Correspondence to: Aref Albakri, St-Marien hospital Bonn Venusberg, Department of internal medicine, Bonn, Germany, E-mail: arefalbakri@yahoo.com

Key words: diastolic heart failure, diastolic dysfunction, normal ejection fraction

Received: November 02, 2018; Accepted: November 22, 2018; Published: November 26, 2018 

therapy

Ventricular filling occurs in two phases: early rapid filling and late filling phase. In the early rapid filling phase, the pressure gradient between LA and the ventricles is high with rapid ventricular filling [12]. Under normal conditions, approximately $70 \%$ of ventricular filling occurs during the early rapid filling phase. As diastole progresses, ventricular pressure increases reducing the rate of ventricular filling (also known as the diastasis phase). In late diastole, there is terminal ventricular filling resulting from a sudden increase in LA pressure due to LA contraction/systole phase. When ventricular pressure rises above the atrial pressure, the mitral and tricuspid valve close completing diastole [12,13]. Diastolic dysfunction occurs when ventricular relaxation, early filling, diastasis, late filling, or LV and LA compliance is prolonged, slowed or incomplete [14]. Conditions such as myocardial ischemia or LV hypertrophy prolong active relaxation. In such circumstances, shortening of diastole due to tachycardia or the loss of atrial systole due to the development of atrial fibrillation could cause significant hemodynamic compromise in DHF patients [13].

Diastolic heart failure: Despite the long-established recognition, a strict definitional uniformity of DHF in both scholarly and practitioner literature has remained elusive. Overtime, definitions of HF based on pathologic mechanisms and/or symptoms have been wide-ranging and prone to misclassification (Table 1).

Although all these early definitions were accurate and described pathologic mechanisms or functional abnormalities, their applicability in clinical practice was problematic. Taken together, the early definitions indicated that DHF is a syndrome characterized by typical symptoms and signs of heart failure, a preserved ejection fraction (EF) and a predominant abnormal diastolic function. Other recent definitions have described DHF as heart failure with preserved systolic function or heart failure with normal or near normal ejection fraction [1820]. From a conceptual perspective, DHF develops when ventricular chamber is not able to accept adequate volume of blood during diastole at normal diastolic pressure and to maintain appropriate stroke volume. These abnormalities result from a delay in ventricular relaxation and/or increased ventricular stiffness, and produce symptoms that occur even at rest - New York Heart Association (NYHA) functional class I - or occur with normal physical activities - NYHA II [8] (Table 2).

\section{Epidemiology}

Patients with DHF comprise a large and important sub-population of HF patients. They frequently experiences delayed diagnosis and limited treatment options, usually based on therapies validated for SHF patients [18]. Since research interest on DHF is growing, knowledge of its precise epidemiology will provide insight into population characteristics that could potentially predispose individuals to DHF. The basis of the current assessment of the epidemiology of DHF are systematic review, population-based epidemiological studies and large international trials.

Systematic reviews: Heart failure was identified as an emerging epidemic in 1997 reflecting increased incidence, increased survival leading to increased prevalence or both. Today, the epidemic of HF is changing, estimated to affect more than 23 million people [22] with a prevalence greater than 37.7 million people globally [23]. However, the precise prevalence rates of diastolic dysfunction and DHF based on adequate echocardiography assessment are lacking. A recent metaanalysis of 28 studies from 25 different study populations finds the median prevalence of LV diastolic dysfunction in older adults $(>60$ years) is $36.0 \%$ (range $15.8 \%$ to $52.8 \%$ ) and DHF is $4.9 \%$ (range $=3.8 \%$ to $7.4 \%$ ). The prevalence of DHF has increased steadily and is now the dominant subset of HF relative to SHF, whose prevalence has had a marked decrease over the past decade because of marked improvements in medical and device therapies [24].

Epidemiological studies: Large-scale epidemiological studies on cardiovascular diseases also provide estimations of the prevalence of DHF. The Cardiovascular Health Study (CHS) was the first large epidemiology study $(\mathrm{N}=4,842)$ to examine $\mathrm{HF}$ in older adults (mean age $=77 \pm 5$ years), which established DHF is a cardiogeriatric syndrome whose prevalence increased with ageing, from 6.6\% at age 65-69 years to $14 \%$ at $>85$ years. Its prevalence shows a high gender discrepancy - more prevalent in women (67\%) than in men $(42 \%)[25,26]$, which support the findings of the Framingham Heart Study [27-30]. Recently, the Candesartan in Heart Failure-Assessment of Reduction in Mortality and Morbidity (CHARM) trial [31] supported the findings that DHF has a significant gender disparity, with disproportional higher rates in women. In addition, patients with DHF were more often hypertensive and older but less likely to have a history of myocardial infarction (MI). The Irbesartan in Heart Failure with Preserved EF (I-Preserve) trial also reported a pronounced DHF prevalence in women $(60 \%)$, older adults and hypertensive patients [32].

International trial data: International trial data suggests DHF accounts for between $44 \%$ and $72 \%$ of all cases of HF [33]. Patients with DHF from the U.S. and Canada have the highest prevalence; those from Western Europe have intermediate rates; and those from Eastern

Table 1. Definitions of diastolic heart failure overtime

\begin{tabular}{|l|l|}
\hline Author, Year [Ref \#] & Definition \\
\hline Lewis, 1933 [15] & A condition in which the heart fails to discharge its contents adequately. \\
\hline Braunwald, 1980 [16] & $\begin{array}{l}\text { A pathophysiological state in which abnormality of cardiac function is responsible for the failure of the heart to pump blood at the rate commensurate with } \\
\text { requirements of the metabolizing tissues. }\end{array}$ \\
\hline Brutsaert et al. 1993 [17] & $\begin{array}{l}\text { A condition resulting from increased resistance to filling of one or both ventricles leading to symptoms of congestion due to inappropriate upward shift of } \\
\text { the diastolic pressure-volume relation. }\end{array}$ \\
\hline Zile \& Brutsaert, 2002 [14] & $\begin{array}{l}\text { A condition in which the ventricular chamber is unable to accept adequate volume of blood during diastole at normal diastolic pressures and at volumes } \\
\text { sufficient to maintain an appropriate stroke volume. }\end{array}$ \\
\hline Katz \& Zile, 2006 [8] & A clinical syndrome in which patients with heart failure have little or no ventricular dilatation and significant, often dominant diastolic dysfunction. \\
\hline
\end{tabular}

Table 2. New york heart association functional classification of heart failure

\begin{tabular}{|c|l|}
\hline Class & Description \\
\hline I & No limitation: ordinary physical activities does not cause fatigue, dyspnea or palpitation. \\
\hline II & Slight limitation of physical activity: comfortable at rest. Ordinary physical activity may cause fatigue, dyspnea, palpitation or angina. \\
\hline III & Marked limitation of physical activity: patients may be comfortable at rest but less than ordinary activity will lead to symptoms \\
\hline IV & Inability to carry out any physical activity without discomfort: symptoms of heart failure are present even at rest and physical activity increases discomfort. \\
\hline
\end{tabular}

Adapted from the Criteria Committee of the New York Heart Association [21] 

therapy

Europe and Russia have the lowest rates [34]. However, prevalence of DHF in middle- and low-income countries is not well-defined [35]. In Olmsted County cohort, the proportion of DHF relative to the incident cases of HF rose from $38 \%$ in 1986 to $48 \%$ in 2000 and to $57 \%$ in 2010 [36,37]. The American Heart Association (AHA) Get With The Guidelines (GWTG) reported the proportion of DHF hospitalized patients increased from $33 \%$ in 2005 to $39 \%$ in 2010 [38], with higher readmission rates but lower HF-related deaths compared to SHF [39]. Holistically, the current epidemiologic evidence suggests the prevalence and incidence of DHF is rising relative to SHF, and with a higher prevalence among older adults, women and hypertensive patients.

\section{Prognosis}

Mortality and hospitalization: Patients with DHF have a more favorable prognosis compared to those with SHF. Community samples indicate HF-related morality rates of DHF ranges between $4 \%$ and $8 \%$ compared to SHF ranging between $10 \%$ and $15 \%[25,40]$. However, DHF mortality rates are four to five times higher relative to adults with preserved diastolic function, demonstrating the serious clinical implications of DHF [40]. Young age ( $<65$ years) have favorable shortterm survival and re-hospitalization rates compared to SHF patients but the rates are similar for patients $\geq 75$ years [41-44]. Older adults with DHF are less likely to receive optimal benefits with conventional HF medication - beta-blockers and angiotensin converting enzyme (ACE)-Inhibitors [25,45].

Predictors of poor prognosis: Diastolic heart failure (DHF) is a more cardiogeriatric syndrome compared to SHF and thus older age is an important independent predictor of poor prognosis [46-49]. Mortality rates of older adults with DHF is comparable to that of SHF patients [41-44]. Other significant predictors of poor prognosis in DHF patients are comorbidities particularly hypertension, diabetes and obesity, all known to cause or exacerbate DHF [23,46]. Hypertension is the most prevalent co-morbidity burden among DHF patients. In the Olmsted County cohort, $89.3 \%$ of DHF patients were hypertensive [35]. The lifetime risk for hypertensive DHF patients with blood pressure $>160 / 90 \mathrm{mmHg}$ is twice that of DHF patients with blood pressure < $140 / 90 \mathrm{mmHg}$ [50]. Other less significant predictors of poor prognosis are the presence of systolic dysfunction, peripheral vascular disease, a history of cancer, renal dysfunction and anemia [51]. The presence of DHF in the early stages of acute MI also significantly increases the risk of death $[4,14,44]$. Race (African Americans) and low socio-economic status mays also predict poor prognosis [52]. However, additional research evidence is warranted to determine the influence of health care access among medically under-served populations with poor control of hypertension, diabetes and higher rates of obesity to isolate the role of race and socio-economic disparities on DHF prognosis.

\section{Etiology and pathophysiology}

\section{Etiology}

The high prevalence of comorbidities in DHF patients compared to SHF strongly suggest their involvement in the onset of DHF. The main clinical disorders (or comorbidities) that are suspected to contribute to the onset or progressive development of DHF are hypertension, obesity and diabetes. Other less common disorders include hypertrophic cardiomyopathy (HCM), valvular heart disease and coronary artery disease $(\mathrm{CAD})[7,53]$.

Hypertension: Increasing evidence strongly suggests hypertension plays a central role in the development of diastolic dysfunction. Findings from animal models support findings that diastolic dysfunction is very common in hypertensive patients because of increased afterload (pressure overload) [49]. Epidemiological studies have also consistently reported that hypertension increases the risk for developing DHF up to three times compared with normotensive patients $[28,55]$. In the Framingham Heart Study, hypertension preceded DHF in $91 \%$ of the patients [56]. In trials based on Doppler echocardiography, up to $20 \%$ of patients with borderline or mild hypertension had impaired diastolic filling, suggesting the prognostic significance of echocardiography screening to determine and prevent the progression of diastolic dysfunction to DHF in at-risk hypertensive patients [5759]. Hypertension increases the risk of DHF by increasing LV afterload leading to delayed isovolumic relaxation time, elevated filling pressures and reduced end-diastolic volume $[1,14,5760,61]$. These pathologic changes contribute to abnormal stretching of cardiomyocyte, activation of the sympathetic nervous system and progressive secretion of neurohormonal and cytokines [62], which lead to cardiomyocyte apoptosis, ventricular remodeling in turn increasing LV mass leading to further loss of myocardial compliance [63].

Obesity: Obesity, defined as body mass index $>30 \mathrm{~kg} / \mathrm{m}^{2}$, is a growing epidemic and may play an important role in the development of diastolic dysfunction in obese individuals [64]. Echocardiography evidence in 4,281 patients with $<50 \%$ coronary stenosis associated obesity with greater LV mass, LV wall thickness, and LV end-diastolic diameter [65]. Obesity has also been reported as a contributing factor for ventricular remodeling, impaired LV relaxation and elevated LV filling pressures, which lead to diastolic dysfunction and ultimately the development of DHF [49]. Gender differences in obese patients may also contribute to the development of DHF since overweight and obese women have a higher prevalence of DHF compared to overweight and obese men [66].

Diabetes: Diabetic patients are two to five-fold more likely to have DHF compared to non-diabetic patients $[67,68]$. Diastolic dysfunction has been frequently identified as the initial sign in patients with diabetic cardiomyopathy [69]. Zabalgoitia et al. [69] investigated 86 young (mean age 43 years), normotensive diabetic patients and found $40 \%$ had diastolic dysfunction, $26 \%$ had impaired ventricular relaxation and $17 \%$ pseudo-normalization on tissue Doppler echocardiography [70]. The Strong Heart Study (SHS) [71] involving 2,411 Native Americans found impaired ventricular relaxation was common in diabetic patients. Moreover, patients with co-occurring diabetes and hypertension showed greater abnormalities in LV relaxation compared to patients with diabetic alone [71]. In diabetic patients, poor glycemic control and elevated levels of hemoglobin A1c (HbAlc) was associated with impaired LV relaxation and increased risk of DHF. For every $1 \%$ increase in HbAlc, the risk of DHF increases by $8 \%$ [72]. The Strong Heart Study (SHS) [71] also reported a direct correlation between increased urinary albumin excretion and LV diastolic dysfunction. The study associated diabetic-related pathologic alterations in myocardial glucose and increased fatty acid oxidation with structural alterations of the myocardium, cardiomyocyte hypertrophy, excessive collagen deposition, interstitial fibrosis and intra-myocardial micro-angiopathy (micro vascular disease), all of which independently contribute to the development of diastolic dysfunction and ultimately DHF [71]. Since diabetes is a significant risk factor in the development of DHF, its management should be incorporated in therapeutic interventions of DHF.

Comorbidities: Diastolic HF is a cardiogeriatric syndrome - has a very high prevalence in older adults. As a result, age-related and pathologic changes are more likely to contribute to the development 

therapy

or exacerbation of the syndrome [46-49]. Significant age-related hemodynamic changes include a decline in the maximal heart rate, cardiac output, and maximal oxygen consumption. Although stroke volume may remain unchanged or decrease slightly, systemic vascular resistance increases leading to increased blood pressure and afterload $[6,14,40,73]$. Ageing is also associated with greater LV stiffness, reduced LV compliance, increased LV wall thickness, decreased myocardial vascular responsiveness to beta-adrenergic stimulation and lower mitochondrial response to high demand for adenosine triphosphate production (ATP) [73]. Due to older age in many DHF patients, the presence of multiple comorbidities may lead to or aggravate DHF. In a study of U.S. Medicare beneficiaries, hospitalized HF patients frequently presented with at least six comorbidities [74,75]. Polypharmacy (the concurrent use of multiple medication by a patient) is common in older adults with DHF and drug-to-drug reactions may present potential injurious consequences exacerbating the progress of DHF. Poor renal function is also associated with poor prognosis and outcomes in older adults with DHF [49].

\section{Pathophysiology}

Whereas diastolic LV dysfunction has long been recognized as the principle contributor to DHF, recent evidence suggests that increased myocardial stiffness due to hypertrophy and myocardial infarction, and abnormal (delayed) relaxation (due to ischemia and pressure overload) contribute to DHF pathophysiology (Figure 1).

Myocardial stiffness: Stiffness of the extracellular matrix (ECM) and cardiomyocytes are the two key components involved in the regulation of myocardial stiffness [54]. The stiffness of the ECM primarily depends on the total amount of collagen, the abundance of Collagen Type 1 or the degree of collagen cross-linking [76]. In DHF patients, all the three mechanisms are involved. The key causes of excessive deposition of collagen type 1 are an imbalance between its synthesis and degradation. Exaggerated synthesis and/or depressed degradation of Collagen
Type 1 leads to its abundance and consequent excessive deposition in myocardial tissues. Patients with DHF and hypertension [77] or aortic stenosis [78] have been shown to have decreased ECM degradation caused by the downregulation of matrix metalloproteinases (MMPs) and upregulation of tissue inhibitors of MMPs (TIMPs). Based on these findings, there are proposals that serum levels of TIMPs are potential biomarkers for the development of DHF in patients with arterial hypertension [79]. On the other hand, patients with dilated cardiomyopathy (DCM) have increased ECM degradation due to the upregulation of MMPs [80]. The distinct expression profiles of MMPs and TIMPs have been shown to correspond with unequal patterns of collagen deposition on the myocardial tissues with interstitial fibrosis in DHF patients, and both replacement and interstitial fibrosis in DCM patients [81].

In addition to ECM, cardiomyocyte stiffness contributes to myocardial stiffness and leads to the development of diastolic dysfunction in DHF patients. The contribution of cardiomyocyte has been supported by endomyocardial biopsies of the LV revealing a third of DHF patients have normal collagen volume fraction but with LV enddiastolic pressure, systolic wall stress and stiffness modulus comparable to DHF patients with raise collagen volume fraction [83]. Several other studies have supported the role of cardiomyocyte stiffness by reporting greater intrinsic cardiomyocyte stiffness in DHF patients $[81,83,84]$ as well as in patients with LV hypertrophy due to congenital heart disease [85]. Increased cardiomyocyte stiffness had also been linked to titin (a cytoskeletal protein) expressed in two main isoforms - a stiffer N2B and a more compliant N2BA [86]. Earlier research demonstrated that the N2B:N2BA titin isoform ratio is elevated in remodeled explanted hearts from DCM patients compared to donor hearts [87-89]. Whereas variation in titin isoform expression may contribute to changes in myocardial passive stiffness, increased passive stiffness in an impaired myocardium could also result from alterations in phosphorylation state of titin $[90,91]$.

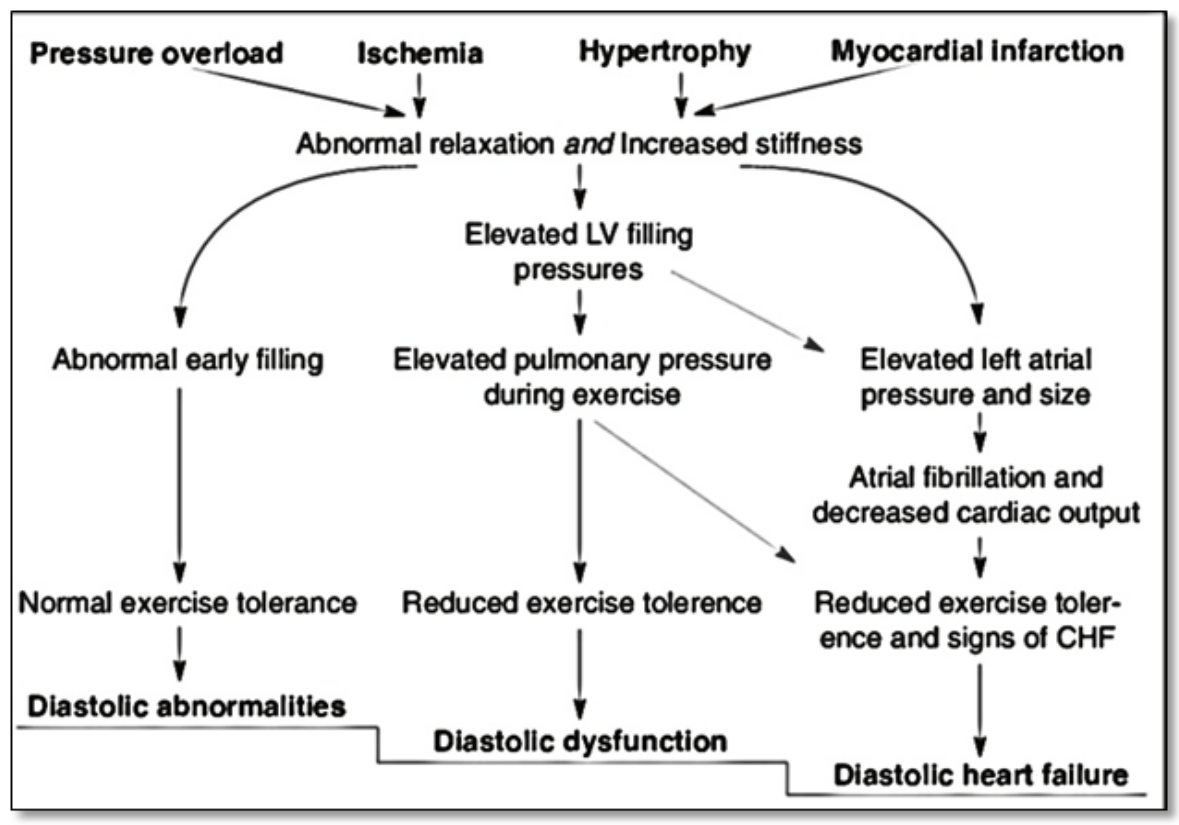

Figure 1. Pathophysiology of diastolic heart failure [7]

Impaired relaxation and increased stiffness contribute to diastolic filling abnormalities and normal exercise tolerance in the early stages of DHF. Progression of DHF increases pulmonary pressure during exertion with reduced exercise tolerance. Further increases in filling pressure increases left atrial pressure and size and further decrease in exercise tolerance with manifestations of clinical signs of HF. Adapted from Mandinov et al. p. 822 [7] 

therapy

Delayed relaxation: A large proportion of patients with DHF are hypertensive. Ischemia and/or hypertension may cause systemic vascular dysfunction leading to pressure overload in turn resulting in concentric LV hypertrophy, fibrotic remodeling and slowed LV relaxation $[7,54]$. Both invasive and non-invasive LV assessment reveal DHF patients have a more impaired LV relaxation and diastolic stiffness relative to healthy or hypertensive controls [92-95]. In addition to pressure overload, cross-bridge detachment may contribute to delayed isovolumic relaxation time, which is a major pathologic mechanism of DHF. Delayed LV relaxation leads to decreased LV stroke volume particularly at higher heart rates compared to normal hearts, which accelerates LV relaxation [54]. Furthermore, LV relaxation depends on cross-bridge detachment and sarcoplasmic reticular calcium ion reuptake [96] and nitric oxide signaling, which facilitates cross-bridge detachment [97]. The process of cross-bridge detachment is energy consuming, which could cause myocardial energy deficit contributing to slow LV myocardial relaxation. Recent studies based on myocardial phosphorous magnetic resonance spectroscopy revealed decreased myocardial creatinine phosphate/adenosine triphosphate ratio in DHF patients compared to normal controls suggesting reduced myocardial energy reserve $[98,99]$. Prolonged delayed relaxation may lead to abnormal early filling, increased intolerance to normal exercise and ultimately the development of diastolic abnormalities [12,13].

The combined effect of LV myocardial stiffness and delayed relaxation causes an elevation of LV filling pressures, elevated pulmonary pressure during exercise, reduced exercise tolerance and finally diastolic dysfunction. Myocardial stiffness and abnormal relaxation may also cause diastolic dysfunction and heart failure, through the elevation of left atrial (LA) pressure and size. Chronic high arterial hypertension (increased atrial pressure) may cause structural and electric remodeling leading to the development of atrial fibrillation, decreased cardiac output, reduced exercise tolerance and typical signs of HF ultimately leading to DHF [7].

\section{Clinical presentation and evaluation}

\section{Clinical presentation}

Clinical signs and symptoms that DHF patients frequently present with include exertional dyspnea, fatigue, orthopnea, paroxysmal nocturnal dyspnea, peripheral edema, and exercise intolerance. In addition, DHF patients may also exhibit pulmonary congestion and abdominal bloating largely due to hepatic congestion. Since a large proportion of DHF patients are older adults, it is important to consider atypical symptoms including lethargy, malaise, confusion, irritability and decreased exercise tolerance [40,100,101,102]. Even with preserved LVEF, DHF patients frequently experience significantly reduced exercise tolerance suggesting little correlation between LVEF and exertional intolerance [103-105]. Many factors could explain reduced exercise intolerance in DHF patients. Specifically, reduced lung compliance resulting from increased LV diastolic and pulmonary venous pressure often results in dyspnea, lower stroke volume and cardiac output despite preserved LVEF. Despite preserved LVEF, DHF patients exhibit decreased stroke volume and cardiac output. Finally, because many DHF patients are older and in many cases sedentary, physical deconditioning is common, which may increase peripheral musculoskeletal alterations leading to increased symptom severity and decline in functional status [54].

\section{Clinical evaluation}

The call for developing standardized criteria for the diagnosis of DHF begun in 2000. By then, many proposals of clinical evaluation of DHF relied on three key factors (a) a hierarchical determination of definitive evidence of congestive heart failure; (b) objective evidence of normal systolic function in proximity to the congestive heart failure event; and (c) objective evidence of LV diastolic dysfunction [106]. Overtime, with addition of new evidence on DHF that subtle abnormalities in systolic function maybe present in some DHF patients, parameters for the diagnosis of DHF evolved. As a result, the latest European Society of Cardiology (ESC) [20] and the American College of Cardiology Foundation/American Heart Association (ACCF/AHA) Task Force [107] on practice guidelines termed DHF as HF with preserved EF. The recommended diagnosis of DHF is thus largely achieved by the exclusion of other cardiac conditions presenting with similar clinical signs and symptoms. Both the ESC and ACCF/ AHA guidelines recommend that clinical evaluation should fulfill the following three obligatory conditions to exclude other probable cardiac causes and confirm the diagnosis of DHF:

\section{The presence of signs and symptoms of heart failure;} and

The presence of normal or mildly abnormal LV systolic function;

Demonstrable evidence of structural heart disease or diastolic LV dysfunction.

Figure 2 is a schematic illustration of diagnostic workout of DHF showing the initial assessment (clinical history, physical examination and electrocardiogram) to determine the probability of HF, assessment of the levels of serum natriuretic peptides to exclude diagnosis of DHF, and echocardiography to assess cardiac structure and function to confirm diagnosis of DHF.

Presence of signs and symptoms: The 2016 ESC heart failure guidelines recommend that in non-acute clinical settings, the first step in the diagnosis of DHF is to assess the probability of HF in suspected patients based on the determination of known clinical signs and symptoms of HF. In addition, symptoms are important prognostic predictors because the persistence of symptoms despite optimal treatment may suggest the need for additional therapy and worsening of symptoms may suggest the need for immediate medical attention [20,107]. Initial evaluation of DHF should include the assessment of detailed clinical history, physical examination and laboratory assessment. Obtaining and assessing clinical history of patient suspected with DHF is highly recommended to identify known HF risk factors such as a history of CAD, MI or revascularization, history of arterial hypertension, previous or current exposure to cardiotoxic drug or radiation and the use of diuretics. Patients with no relevant medical history such as a potential cause of cardiac injury are unusual to develop HF whereas those with a history of MI in the presence of appropriate signs and symptoms have a higher likelihood of HF [108-111].

Physical examination and laboratory tests are recommended to identify typical HF signs and symptoms. Specific signs of HF to look for include elevated jugular venous pressure, hepatojugular reflux, third heart sound, and laterally displaced apical pulse while typical symptoms include breathlessness, orthopnea paroxysmal nocturnal dyspnea, reduced exercise tolerance, fatigue, and lower-extremity edema [20]. Careful consideration of obese, older adults and patients with chronic lung disease is required because they may present with atypical symptoms [112-114]. Younger HF patients may also have a different etiology, clinical presentation and outcome compared to older adults $[115,116]$. The goal of physical examination is to identify HF signs such as pulmonary rales, bilateral lower-extremities edema, heart murmur, jugular venous dilatation and laterally displaced or broadened 


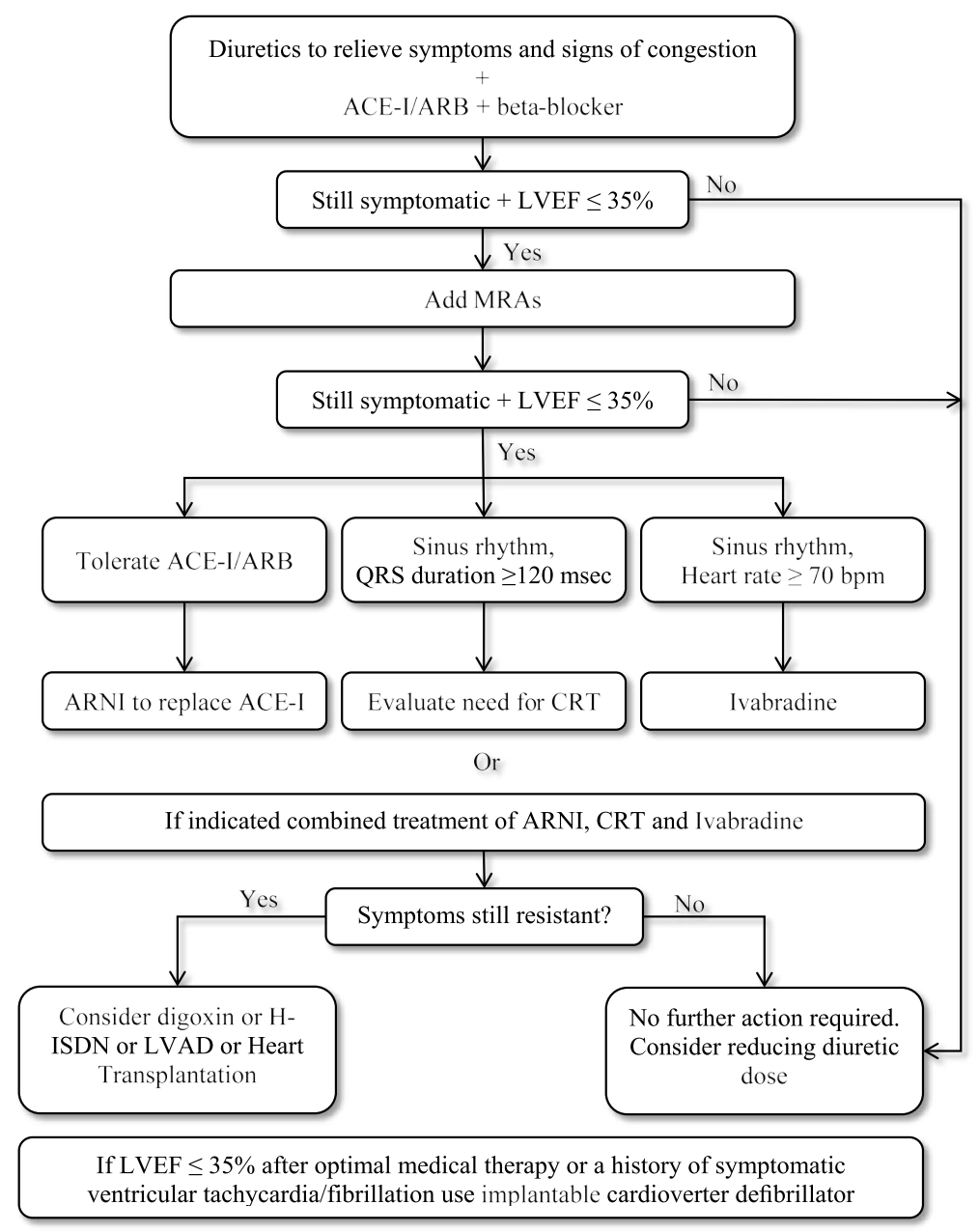

Figure 2. General diagnosis criteria for heart failure

Diagnosis of DHF begins with the assessment of the probability of HF by evaluating clinical history for risk factors (such as a history of precipitating cardiac conditions), presenting symptoms and physical examination and resting electrocardiogram. If all findings are normal, DHF is unlikely. If at least one outcome is abnormal, the concentration of serum natriuretic peptides should be assessed to identify patients for cardiac examination using echocardiography (those having levels above the cut-off points). Evidence of normal or mild systolic function and diastolic dysfunction on echocardiography confirms the diagnosis of DHF. Adapted from the 2016 ESC Guidelines on Heart Failure, p. 2141 [20]

apical beat. In addition, abnormal echocardiography (ECG) findings increase the likelihood of diagnosis (or rule out diagnosis) and provide information on etiology such as MI and indications for therapy such as anticoagulation for atrial fibrillation (AF), pacing for bradycardia, and cardiac resynchronization therapy (CRT) for the case of broadened QRS complex [117,120].

If at least one of the initial tests (clinical history, physical examination or ECG) is abnormal, there is a likelihood for HF and the ESC recommends the assessment of serum natriuretic peptides (NPs). However, if all initial test results are normal, there is a very low likelihood of HF [20]. Although measurement of serum NPs is not routinely done in clinical practice, it is highly recommended in nonacute clinical settings where echocardiography is not immediately available. Elevated serum concentration of NPs establishes an initial working diagnosis and assists in the selection of patients for cardiac examination. Patients with serum concentration below cut-off values strongly suggest the absence of cardiac dysfunction. Cut of values for B-type natriuretic peptide (BNP) and N-terminal pro-BNP (NTproBNP) are $35 \mathrm{pg} / \mathrm{mL}$ and $\geq 125 \mathrm{pg} / \mathrm{mL}$ and in acute settings are $>$ $100 \mathrm{pg} / \mathrm{mL}$ and $>300 \mathrm{pg} / \mathrm{mL}$ respectively [20]. Serum NPs have a high negative predictive values ( $95 \%$ to $98 \%$ ) but lower positive predictive values (66\% to $67 \%$ ) suggesting their value in excluding DHF rather than establishing diagnosis of DHF [121-126]. However, clinicians should consider the presence of cardiac and extra cardiac conditions that may cause an elevation of serum NPs such as AF, older age and renal failure and weaken diagnostic utility of NPs in DHF [127]. Lower serum NPs values in obese patients should also be considered because they have been associated with disproportionally low levels of NPs [20].

Assessment of systolic/diastolic function: The ESC [20] and ACCF/ AHA [107] guidelines recommend cardiac examination for patients with a suggestive clinical history, abnormal physical examination findings or abnormal ECG findings, as well as patients with serum levels above the cut-off points. Cardiac imaging plays a central role in the diagnosis of DHF and guiding treatment by providing objective evidence of normal or mildly reduced systolic function and a predominant diastolic dysfunction to confirm DHF diagnosis. Echocardiography remains the most widespread imaging method in clinical practice for cardiac assessment in patients suspected with DHF because it is accurate, available, safe and inexpensive [128-130]. Values of normal systolic function (LVEF $>40 \%$ ), evidence of structural heart disease (left atrial volume index $>34 \mathrm{~mL} / \mathrm{m}^{2} \mathrm{LV}$ mass index $\geq 115 \mathrm{~g} /$ $\mathrm{m}^{2}$ for males and $\geq 95 \mathrm{~g} / \mathrm{m}^{2}$ for females) and evidence of functional 

therapy

alterations $\mathrm{E} / \mathrm{e}^{\prime} \geq 13$ and mean e' septal and lateral wall $<9 \mathrm{~cm} / \mathrm{s}$ on echocardiography confirms DHF diagnosis. However, caution should be observed when diagnosing DHF in patients with AF. In AF patients, concentration of serum NPs is elevated and thus, diagnosis based on concentration of serum NPs requires stratification using sinus rhythm with a higher cut-off for AF patients. Higher levels of left atrial volume index (LAVI) are also observed in DHF patients and functional parameters of diastolic dysfunction in AF are not well established. The presence of AF might indicated DHF since patients with AF and DHF often have similar characteristics or more advanced HF compared with DHF patients in normal sinus rhythm [20]. If echocardiographic results are inconclusive or non-diagnostic, cardiac magnetic resonance is the best alternative cardiac imaging modality especially useful in patients with complex congenital heart disease [20].

\section{Meta-analysis of diagnostic accuracy of tissue doppler index E/e'}

The hallmark of DHF diagnosis is the presence of normal LV systolic function and a predominant diastolic dysfunction. While objective evidence of LV systolic function is well established (as documented by LVEF $>40 \%$ on echocardiography), quantification of diastolic function in DHF patients is not well defined. The most common parameters used to measure LV diastolic function are invasively determined LV enddiastolic pressure (LVEDP) and pulmonary capillary wedge pressure (PCWP) $[18,20,106]$. However, echocardiography is the mainstay of non-invasive diastolic assessment in DHF patients but utilizes surrogate markers to measure LVEDP $[19,131]$. Myocardial stiffness and delayed ventricular relaxation are the key pathophysiologic mechanisms of DHF contributing to elevated LV filing pressure (LVFP) indirectly assessed by tissue Doppler Imaging (TDI) [131]. Early mitral annular velocity (e') quantified by TDI is a surrogate marker of LV myocardial relaxation ( $\mathrm{e}^{\prime}<8$ to $10 \mathrm{~cm} / \mathrm{s}$ ), which is derived from the location of lateral or septal annulus or mean of lateral and septal and used to indicate impaired myocardia relaxation $[119,131]$. Early mitral annular velocity (e') together with mitral peak early filling velocity (E), the E/e' ratio provides a surrogate estimation of LVFP. Both the ESC and AHA recommend the use of E/e' in the diagnosis of diastolic dysfunction and DHF [20,107]. Values of E/e' lateral $>12 \mathrm{E} / \mathrm{e}^{\prime} \geq 13$ indicates elevated LVFP while E/e' $<8$ indicates normal LVFP $[20,131]$. Intermediate values of $\left(>8 \mathrm{E} / \mathrm{e}^{\prime}<13\right)$ suggest the need for additional echocardiographic tests to determine diastolic dysfunction. Although clinical research extensively uses mean E/e' as a surrogate non-invasive maker for LVEDP, its diagnostic accuracy has not received inconsistent findings [132-134]. This meta-analysis therefore seeks to combine available research evidence to determine the diagnostic accuracy of E/e' in quantifying diastolic dysfunction.

Search strategy and inclusion criteria: The search for primary studies using echocardiography to evaluate LVFP and diastolic dysfunction in DHF patients was done on online databases PubMed, EMBASE and Scopus. The search used various combinations of the following key search words: diastolic dysfunction, diastolic heart failure, echocardiography, normal left ventricular ejection fraction, and left ventricular filling pressure. The inclusion criteria for studies were: (a) recruited patients with suspected with DHF with normal or mildly reduced LEVF; (b) assessed patients using echocardiography for diastolic dysfunction; and (c) provided data on LVFP assessment using E/e. There was no restriction on publication year and language. However, studies were excluded if they had only abstracts, were conference papers or did not provide adequate data for extraction. Additional studies were obtained from screening citations of the included studies and review articles. Two reviewers independently screened all qualifying studies against the inclusion criteria as well as abstracted data from the included studies. Any disagreements encountered during screening or data abstraction was resolved by consensus. The abstracted data included: (Table 3).

Study characteristics and outcomes: Combined online search and citation screening yielded 2,212 unique citations. After elimination based on title and abstract screening, 134 studies were subjected to full text screening against the inclusion criteria. Ultimately, 14 studies were included in this meta-analysis [143-156]. The 14 studies had a combined patient population of 973 patients with DHF and LV ejection fraction $(>40 \%)$. The recruited patients were older (mean age $=62$ years; range (53-71) with an equal gender representation (women $=$ $51 \%)$. Pooled correlation data of 12 studies [143-147,149,150,152-156] show a modest positive correlation between invasively assessed left ventricular end-diastolic pressures (LVEDP) and Tissue Doppler E/e' values ( $r=0.518$; 95\% CI, 0.467 to 0.565 ) (Table 4 , Figure 3 ).

\section{Discussion of Outcomes}

Diagnosis of DHF relies on the determination of typical symptoms and signs of HF accompanied by objective evidence of structural and/ or functional cardiac abnormalities including elevated levels of serum natriuretic peptides (mainly BNP) and abnormal echocardiographic findings [20,106,107]. Definitive diagnosis of DHF also requires

Table 3. Summary of correlation of tissue doppler E/e' with LV end-diastolic pressure

\begin{tabular}{|c|c|c|c|c|c|c|c|c|}
\hline 1st Author & Year & Sample & Mean Age & Women \% & LVEF & Mean E/e' & E/e' (r) & p-value \\
\hline Ommen et al. [143] & 2000 & 64 & $63(12)$ & 39 & $53(5)$ & NR & 0.45 & 0.640 \\
\hline Dokainish et al. [144] & 2004 & 19 & $57(13)$ & 47 & $64(2)$ & $13(1)$ & 0.69 & 0.001 \\
\hline Hadano, et al. [145] & 2005 & 65 & $66(9)$ & 37 & $60(6)$ & NR & 0.41 & 0.001 \\
\hline Kasner et al. [146] & 2007 & 43 & $54(43-60)$ & 56 & $64(58-74)$ & $12(8)$ & 0.71 & 0.001 \\
\hline Wang et al. [147] & 2007 & 50 & $59(16)$ & 28 & $41(22)$ & $15(9)$ & 0.68 & 0.010 \\
\hline Dini et al. [148] & 2010 & 55 & $71(12)$ & 58 & $61(6)$ & $10(4)$ & NR & NR \\
\hline Dokainish et al. [149] & 2010 & 122 & $55(9)$ & 55 & $61(6)$ & NR & 0.68 & 0.001 \\
\hline Kasner et al. [150] & 2010 & 21 & $51(43-60)$ & 52 & $64(60-70)$ & $13(9-16)$ & 0.57 & 0.001 \\
\hline Penicka et al. [151] & 2010 & 20 & $67(9)$ & 75 & $62(4)$ & $11(4)$ & NR & NR \\
\hline Hsiao et al. [152] & 2011 & 75 & $70(11)$ & 83 & $49(11)$ & $14(7)$ & 0.584 & 0.0001 \\
\hline Previtali et al. [153] & 2011 & 100 & $63(11)$ & 81 & $48(16)$ & $12(4)$ & 0.12 & 0.230 \\
\hline Poorrafsanjani et al. [154] & 2014 & 110 & NR & 34 & NR & NR & 0.4 & 0.005 \\
\hline Cameli et al. [155] & 2016 & 20 & $73(10)$ & 25 & $58(2)$ & $8(7)$ & 0.72 & 0.0001 \\
\hline Andersen et al. [156] & 2017 & 209 & $59(12)$ & 39 & $47(21)$ & $14(8)$ & 0.52 & 0.0001 \\
\hline
\end{tabular}

E/e': The ratio of mitral velocity to early diastolic velocity of the mitral annulus

Invasive by cardiac catheterization 
Albakri A (2018) Diastolic heart failure: A review of clinical status and meta-analysis of the accuracy of tissue doppler diagnosis and the efficacy of exercise training therapy

Table 4. Pooled correlation coefficient for LVEDP and doppler E/e

\begin{tabular}{|c|c|c|c|c|c|c|}
\hline \multirow{2}{*}{ Study } & \multirow{2}{*}{ Sample size } & \multirow{2}{*}{ Correlation coefficient } & \multirow{2}{*}{$95 \%$ CI } & \multirow{2}{*}{ P-value } & \multicolumn{2}{|c|}{ Weight (\%) } \\
\hline & & & & & Fixed & Random \\
\hline Ommen et al. [143] & 64 & 0.450 & 0.230 to 0.627 & & 7.08 & 8.90 \\
\hline Dokainish et al. [144] & 19 & 0.690 & 0.343 to 0.871 & & 1.86 & 4.97 \\
\hline Hadano, et al. [145] & 65 & 0.410 & 0.185 to 0.594 & & 7.19 & 8.94 \\
\hline Kasner et al. [146] & 43 & 0.710 & 0.521 to 0.833 & & 4.64 & 7.76 \\
\hline Wang et al. [147] & 50 & 0.680 & 0.495 to 0.806 & & 5.45 & 8.21 \\
\hline Dokainish et al. [149] & 122 & 0.680 & 0.571 to 0.765 & & 13.81 & 10.31 \\
\hline Kasner et al. [150] & 21 & 0.570 & 0.183 to 0.804 & & 2.09 & 5.33 \\
\hline Hsiao et al. [152] & 75 & 0.584 & 0.412 to 0.716 & & 8.35 & 9.30 \\
\hline Previtali et al. [153] & 100 & 0.120 & -0.0783 to 0.309 & & 11.25 & 9.93 \\
\hline Poorrafsanjani et al. [154] & 110 & 0.400 & 0.230 to 0.546 & & 12.41 & 10.12 \\
\hline Cameli et al. [155] & 20 & 0.720 & 0.407 to 0.882 & & 1.97 & 5.15 \\
\hline Andersen et al. [156] & 209 & 0.520 & 0.413 to 0.612 & & 23.90 & 11.09 \\
\hline Total (fixed effects) & 898 & 0.518 & 0.467 to 0.565 & $<0.001$ & 100.00 & 100.00 \\
\hline Total (random effects) & 898 & 0.543 & 0.436 to 0.635 & $<0.001$ & 100.00 & 100.00 \\
\hline
\end{tabular}

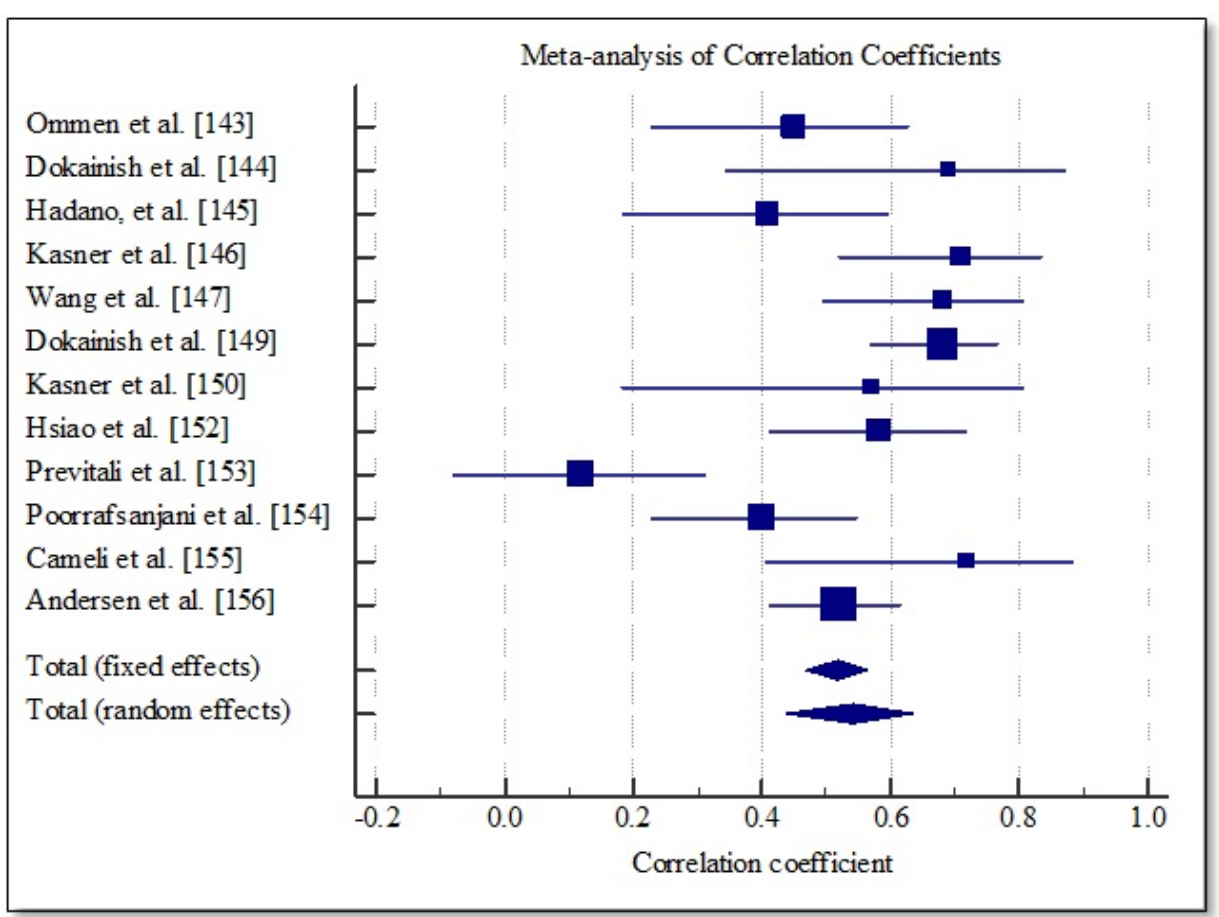

Figure 3. Forest plot showing correlation between LVEDP and tissue doppler E/e'

objective evidence of normal or mildly reduced LV ejection fraction (LVEF > 40\%) and evidence of a predominant diastolic dysfunction [20]. Invasive measurement of LVEDP by cardiac catheterization is considered the gold standard for diagnosis of DHF but is not feasible in routine clinical practice $[106,107]$. The utility of tissue Doppler imaging (TDI) index E/e' in clinical and multi-disciplinary research is increasing for the estimation of LV filling pressure (LVFP) and diastolic dysfunction. Both the 2016 ESC and the 2013 ACCF/AHA guidelines recommend TDI $\mathrm{E} / \mathrm{e}$ ' $\geq 13$ as one of the key markers of diastolic dysfunction. However, the use of TDI E/e' to estimate LVFP in patient cohorts with DHF lacks adequate evidence for use in routine clinical practice. Existing evidence is fragmented and inconclusive because of multiplicity of study designs. The present meta-analysis combined correlation findings reported in studies between LVEDP by cardiac catheterization and TDI index E/e' to determine the overall correlation and accuracy of TDI E/e' in the assessment of diastolic function in DHF patients with normal systolic function (LVEF $>50 \%$ ).
The present meta-analysis finds a modest but significant correlation between LVEDP and E/e' measured by TDI. This finding shows echocardiography assessment of LVFP is accurate and feasible, and supports the increasing use of E/e' as a non-invasive surrogate marker in clinical research [132,133,134,157-158]. Individual studies also report the accuracy of E/e' assessment of LVFP in DHF patients: 74\% [148] and 87\% [156]. However, Penicka et al. [151] reported that mean E/e' $\geq 13$ (the ESC recommended cut-off of diagnosing increased LVFP) accounted for only $30 \%$ in HF patients with normal ejection fraction. In addition, the study reports about 20 to $40 \%$ of DHF patients are in the non-diagnostic borderline $\left(8>\mathrm{E} / \mathrm{e}^{\prime} \geq 13\right)$. The existence of poor diagnostic accuracy of E/e' ( 8 to $15 \mathrm{~cm} / \mathrm{s}$ ) suggests the need of additional echocardiography tests to confirm the diagnosis of diastolic dysfunction in DHF patients. A recent meta-analysis on $\mathrm{E} / \mathrm{e}^{\prime}$ diagnostic accuracy in assessing LVFP and diastolic dysfunction found poor correlation with LVFP. However, a significant proportion of the patients were in the borderline mean E/e' with poor sensitivity (37\%) 

therapy

and high specificity (36\%) [159]. Whereas the present analysis included a majority of patient with normal systolic function (LVEF > 50\%) and demonstrated the feasibility of TDI index E/e' in the measurement of LVFP, its borderline values of 8 to 15 may significantly affect the accuracy of diagnosis, and in these cohort of patients, additional echocardiography tests should be done to confirm diagnosis.

\section{Clinical management}

Status of clinical management: Clinical management of DHF lacks specific treatment guidelines and protocols. However, as new data and analyses on DHF etiology and pathophysiology become available, it might be possible to develop specific treatment for DHF in the near future. Despite the lack of specific treatment, current therapeutic goals of managing DHF are:

To reverse deleterious consequences of diastolic dysfunction such as venous congestion and exercise intolerance);

To eliminate or to reduce the major factors especially cardiac and extra cardiac conditions responsible for diastolic dysfunction; and

To reduce the number and rate of hospitalization, increase hospitalfree survival and improve the overall quality of life [49].

Based on the current evidence, the ACCF/AHA heart failure guidelines only recommend treatment strategies for patients with symptomatic DHF defined by NYHA functional classes II-IV. There is no research evidence supporting beneficial outcomes in the treatment for asymptomatic patients with DHF apart from controlling hypertension, which is the most common modifiable risk factor for DHF [49]. Common clinical management strategies for DHF are medical therapy and treatment for the underlying conditions causing or aggravating diastolic dysfunction.

\section{Medical therapy}

Medical therapy for DHF uses medication developed and validated for patients with SHF. However, there is insufficient evidence on therapeutic efficacy in reducing morbidity, mortality and HF-related hospitalization in DHF patients [20]. The goal of medication is symptom relief and treatment of diastolic dysfunction. Recommended treatment by fluid volume, diuretics or reduced fluid and sodium intake targets to relieve symptoms of pulmonary congestion by reducing LV volume. However, the dosage for diuretics should be used cautiously to avoid hypotension, fatigue or renal impairment. This is especially true since hypotension presents a risk in DHF patients because small changes in diastolic volume may lead to significant changes in afterload and cardiac output, particularly in individuals having a steep diastolic pressure-volume curve [49].

Other recommended medical interventions to reduce LV volume is by targeting the reduction of central blood volume using drugs such as angiotensin-converting enzyme-inhibitors/angiotensin receptor blockers (ACE-I/ARB), which work by blocking the activation of the renin-angiotensin-aldosterone system (RAAS) [54]. The activation of RAAS contributes to reduced cardiac output and increased exercise intolerance in DHF patients $[20,107]$. The recommended treatment for diastolic function include beta-blockers to decrease blood pressure and reduce ventricular remodeling by lowering the harmful neurohormonal and cytokine cascade. Beta-blockers also reduce heart rate to improve diastolic filling and volume, thereby increasing cardiac output. However, there is no evidence on the benefits of medical therapy on reducing morality and hospitalization in DHF patients [49]. In addition to symptom relief and management of diastolic dysfunction, treatment for underlying cardiac condition and comorbidities are recommended to prevent further diastolic dysfunction and improve survival because DHF patients are more likely to die from non-cardiac causes compared to SHF patients [20.49].

\section{Meta-analysis of clinical management}

Pharmacotherapy remains the frontline medical therapy in DHF patients for symptom relief and managing diastolic dysfunction [18]. However, since medication used for DHF adopts medication developed for SHF patients, and that, clinical benefits of medical therapy for DHF patients has not shown convincing reduction on hospitalization and mortality [20], there is need for complementary non-pharmaceutical strategies to improve diastolic function, exercise tolerance, hospitalfree survival and the overall quality of life in these patients. Increasing evidence on the relationship between diastolic dysfunction and reduced exercise tolerance has motivated research into therapeutic values of exercise in improving diastolic function [135]. Already, evidence of exercise training improving cardiorespiratory fitness is emerging in DHF patients [136,137]. Exercise training has also been reported to improve exercise tolerance in sedentary obese and hypertensive patients, who are at a greater risk of developing DHF [138]. Several studies have also evaluated clinical benefits of exercise training as a form of therapy for DHF patients [139-142]. However, these studies did not evaluate hard clinical end-points such as hospitalization and mortality but reported improvement in exercise tolerance and diastolic function. Therefore, the purpose of this meta-analysis is to combine available research findings to determine the therapeutic benefits of exercise training on diastolic function, exertional tolerance, and quality of life in patients with DHF.

Search strategy and inclusion criteria: The search for relevant studies assessing therapeutic benefits of exercise training on DHF patients was carried out on online databases (PubMed, EMBASE, and Cochrane). Various combinations of the following key search terms were used to identify relevant studies: diastolic heart failure, heart failure with normal ejection fraction, exercise training, diastolic function and exercise tolerance. In addition, non-indexed databases such as Google Scholar and institutional library (with the help of the librarian) were searched for additional studies. Studies were included if they met the following criteria: (a) recruited patients with DHF (LVEF > $40 \%$ ); (b) randomized patients into treatment group (exercise training) and control group (not receiving exercise training); and (c) reported quantifiable measures of the effect of exercise training on functional capacity and/or diastolic function. All qualifying studies were included irrespective of the publication year and language. However, studies with only abstract available, conference papers or review articles were excluded. In the case of studies re-using the same patient population, the latest study with the highest number of patients was included. Two reviewers independently carried out study selection and data abstraction and resolved any disagreement through consensus. The abstracted data included author patient population (size, mean age, women percentage, body mass index and New York Functional Class), and clinical outcomes (functional capacity and quality of life) (Tables 5 and 6).

Study characteristics and outcomes: After screening title, abstract and full-text of all the studies retrieved from online searches and citations against the inclusion criteria, five studies published between 2004 and 2013 were eventually included in this meta-analysis [160164]. The combined patients population in the five studies was 237 randomized into exercise training $(\mathrm{n}=230)$ and control group $(\mathrm{n}=$ 

therapy

107), mean age 67.8 years with a greater proportion of women $(70.4 \%)$. At presentation, the patients were generally obese with a high mean baseline body mass index $\left(31.6 \mathrm{~kg} / \mathrm{m}^{2}\right)$. A majority of the patients had either a slight or a marked limitation of physical activity categorized into NYHA Functional Class II (58\%) or NYHA Class III (29\%).

Pooled analysis of the included studies using fixed effect metaanalysis showed significant improvement in functional capacity between exercise training group and control group. Weighted mean difference (WMD) was significantly higher in 6MWT (WMD, 1.202; 95\% CI, 0.898 to 1.505; p < 0.001; Figure 4), and peak amount of oxygen consumption (WMD, 1.619; 95\% CI, 1.298 to 1.939; $\mathrm{p}<0.001$; Figure 5 ) and in quality of life (WMD, -1.070 ; 95\% CI, -1.371 to $-0.817, \mathrm{p}<$ 0.001; Figure 6). One study [162] reported improvement in diastolic function measured by E/e' ratio, which was significant in the exercise training group $(-2.3$; range -3.0 to -1.6$)$ compared to the control group (0.6; range -0.5 to 1.8 ) and cardiac output (6.0 to $7.7 \mathrm{~L} / \mathrm{min} ; \mathrm{p}=0.04)$.

\section{Discussion of outcomes}

Increased exercise intolerance is a key symptom in DHF patients, a strong determinant of quality of life (QoL), independent predictor of survival as well as an emerging therapeutic target. Patients with DHF are relatively older, have reduced exercise tolerance and moderately impaired QoL. In addition, since current medical therapies for DHF have not had convincing reduction in mortality and hospitalization, structured exercise training is being considered as a therapy to improve diastolic function, functional capacity and quality of life. However, evidence supporting clinical benefits of exercise training are inadequate. This meta-analysis sought to combine current research evidence to determine the overall effect of structured exercise training on functional capacity. The analysis finds exercise training conducted for over three months has significant improvement in functional capacity of DHF patients demonstrated by a marked improvement in 6MWT and peak oxygen consumption. One study also reported improvement in diastolic function demonstrated by a significant reduction in $\mathrm{E} / \mathrm{e}^{3}$ ratio compared to control [162].

The present findings support those of a recent meta-analysis study evaluating the effect of exercise training on cardiorespiratory fitness, QoL and diastolic function in patients with heart failure with normal ejection fraction [165]. The study reported significant improvement in cardiorespiratory fitness and quality of life but with no significant improvement in both diastolic and systolic function. However, the study measured diastolic function using $\mathrm{E} / \mathrm{A}$ ratio and early

Table 5. Summary of patient characteristics in the included studies

\begin{tabular}{|c|c|c|c|c|c|c|c|c|}
\hline 1st Author [Ref \#] & Publication Year & ET (n) & Control (n) & Mean Age (yrs.) & Women (\%) & BMI $\left(\mathrm{kg} / \mathrm{m}^{2}\right)$ & NYHA II (\%) & NYHA III (\%) \\
\hline Gary et al. [160] & 2004 & 16 & 16 & $68(11)$ & 100 & $34(7)$ & 41 & 59 \\
\hline Kitzman et al. [161] & 2010 & 26 & 27 & $70(6)$ & 83 & $30(6)$ & 51 & 21 \\
\hline Edelmann et al. [162] & 2011 & 44 & 20 & $64(8)$ & 55 & $31(6)$ & 84 & 16 \\
\hline Smart et al. [163] & 2012 & 12 & 13 & $67(6)$ & 42 & $31(6)$ & 64 & 0 \\
\hline Kitzman et al. [164] & 2013 & 32 & 31 & $70(7)$ & 72 & $32(7)$ & 51 & 49 \\
\hline
\end{tabular}

BMI: Body Mass Index; ET: Exercise Training; NYHA: New York Heart Association

Table 6. Summary of clinical outcomes on exercise training on DHF patients

\begin{tabular}{|c|c|c|c|c|c|c|c|}
\hline \multirow[t]{2}{*}{ 1st Author [Ref \#] } & \multirow[t]{2}{*}{ Duration (Months) } & \multicolumn{3}{|c|}{ Changes in Exercise Training Group } & \multicolumn{3}{|c|}{ Changes in Control Group } \\
\hline & & $6 \mathrm{MWT}$ & $\mathrm{V} 02 \mathrm{~mL} / \mathrm{kg} / \mathrm{min}$ & QoL & $6 \mathrm{MWT}$ & $\mathrm{V} 02 \mathrm{~mL} / \mathrm{kg} / \mathrm{min}$ & QoL \\
\hline Gary et al. $[160]$ & 3 & 203 & NR & -5 & -92 & NR & -4 \\
\hline Kitzman et al. [161] & 4 & 165 & 2.3 & -7 & 48 & -0.3 & -2 \\
\hline Edelmann et al. [162] & 3 & 78 & 2.6 & -8 & 56 & -0.7 & -2 \\
\hline Smart et al. [163] & 4 & NR & 2.8 & -4.8 & NR & 0.8 & -2 \\
\hline Kitzman et al. [164] & 4 & 128 & 1.6 & -10 & 33 & 0.2 & -3 \\
\hline
\end{tabular}

QoL: Quality of Life; V0: Ventricular Oxygen; 6 MWT: Six-Minute Walk Test

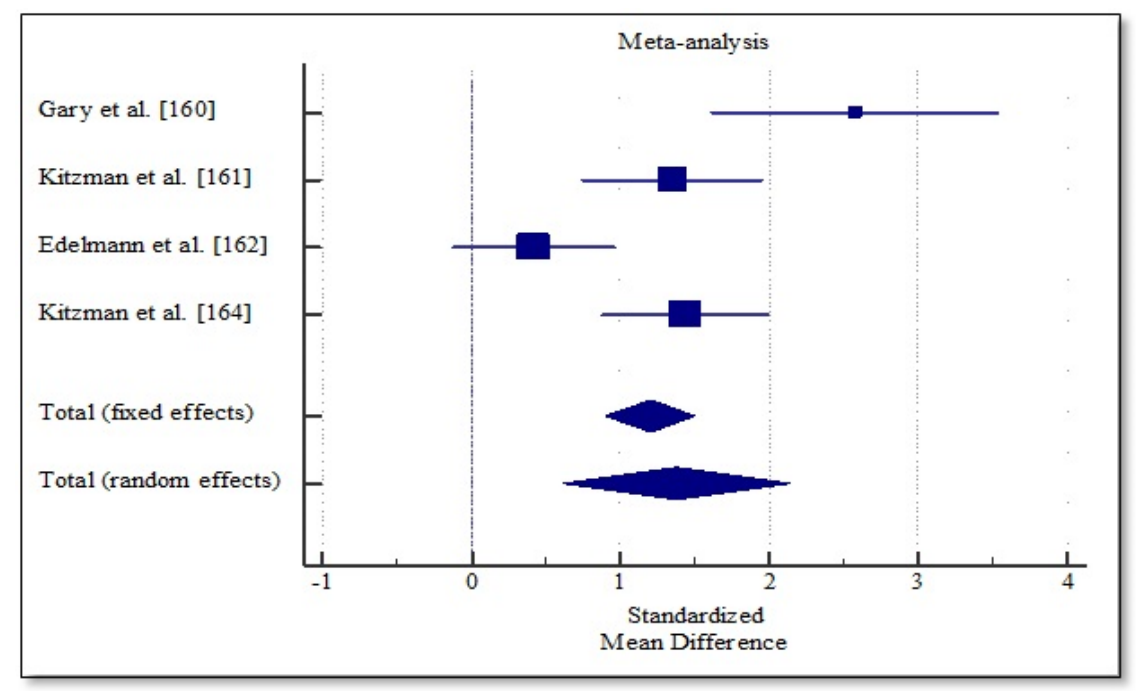

Figure 4. Weighted mean differences in 6MWT 


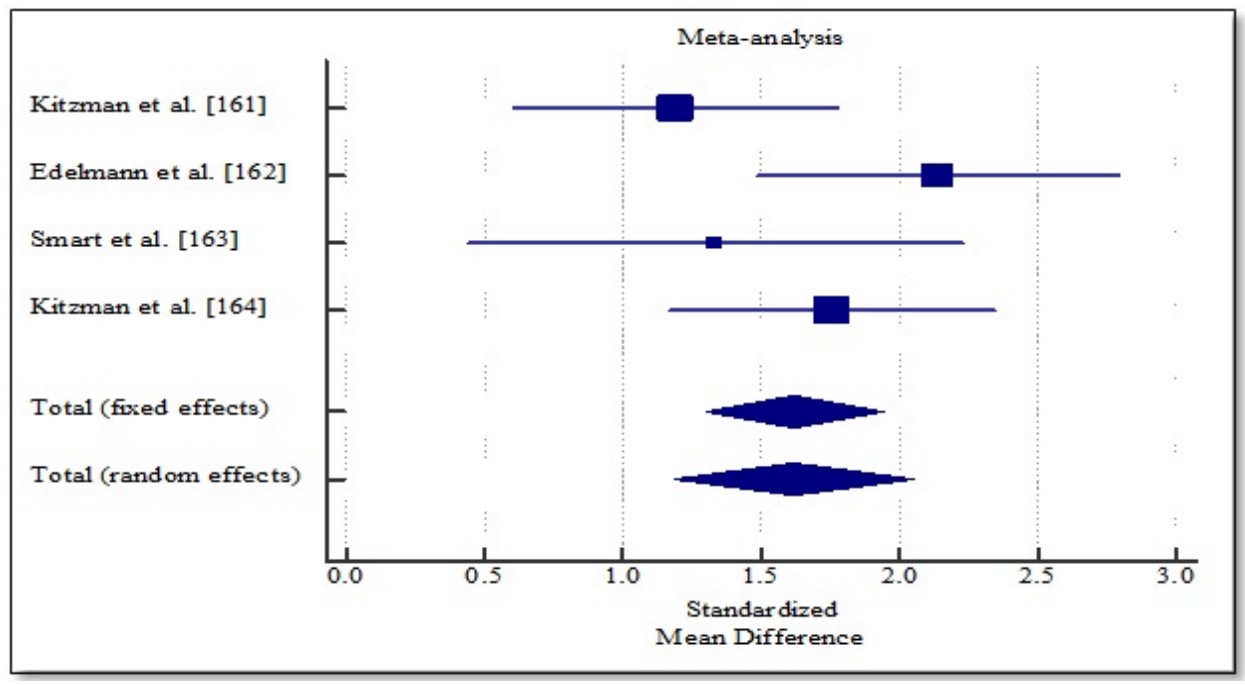

Figure 5. Weighted mean difference in peak $\mathrm{VO}_{2}$ consumption

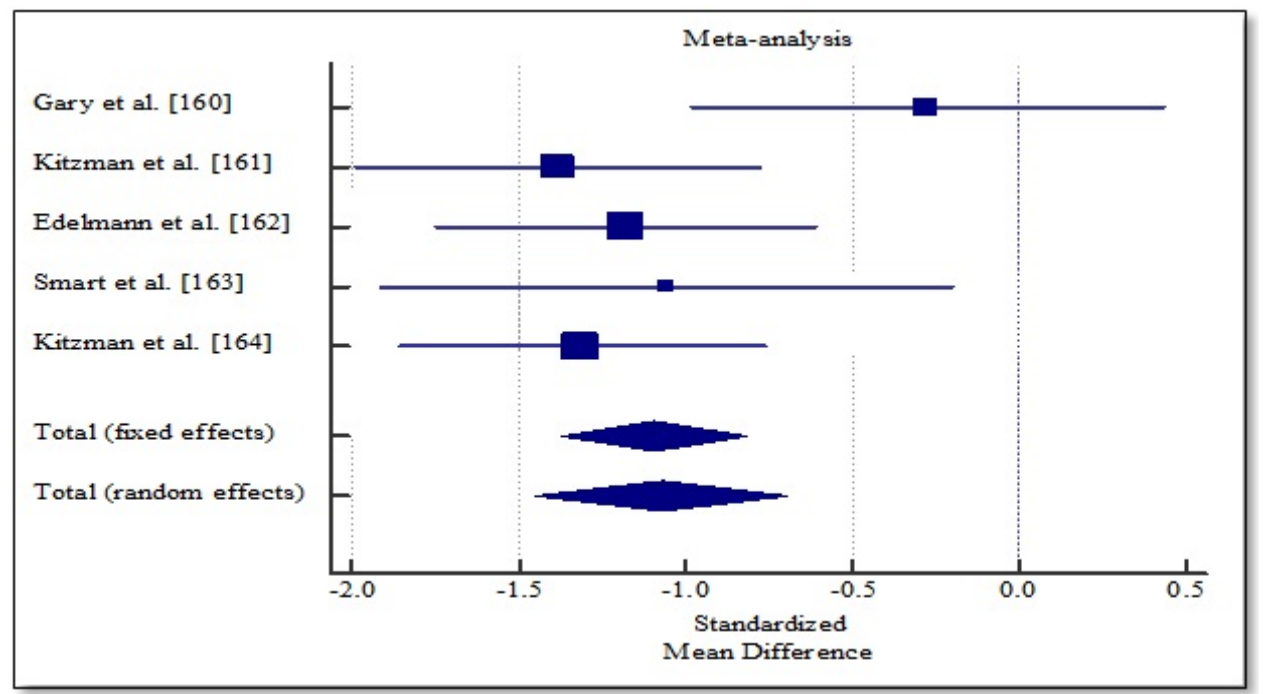

Figure 6. Weighted mean difference in quality of life

deceleration time rather than the more specific E/e' ratio recommended by the latest ESC HF guidelines [20]. Previous trials have also reported structured exercise training improves exertional intolerance and QoL in asymptomatic hypertensive patients at risk of developing DHF as well as in HF patients with reduced ejection fraction $[138,166]$. In a recent randomized controlled trial evaluating a 10-year effect of exercise training on chronic heart failure patients, exercise was feasible and safe therapeutic intervention for over ten years, producing significant improvement in both functional capacity and quality of life. Longterm structured exercise improved heart rate, peak oxygen uptake after one year but resting ejection fraction required longer than one year to register significantly higher levels [167].

Although the exact mechanism through which exercise improves functional capacity and quality of life remains unclear, emerging evidence suggests improvement in diastolic function [137,168]. Other proposed mechanisms with inconclusive evidence include increased stroke volume and cardiac output and improvement in arterial stiffness [265]. Further studies on the relationship between exercise training and diastolic functions would provide additional evidence to determine the mechanisms through which exercise training improves functional capacity and quality of life. With demonstrated therapeutic benefits of exercise training therapy on functional capacity, DHF patients could obtain clinical benefits by combining exercise therapy and standard medical therapy. Exercise training could improve hospital free survival and improve quality of life [167]. However, additional study are warranted to establish whether a dual-therapy of exercise training and medication would have convincing outcomes on reducing HF-related hospitalization, mortality and improve quality of life.

\section{Conclusion}

Diastolic heart failure (DHF) is a cardiogeriatric syndrome characterized by symptoms of dyspnea, fatigue and peripheral edema, normal or mildly reduced left ventricular ejection fraction and a predominant abnormality in diastolic function. DHF accounts up to a half of all cases of heart failure (HF) with a higher prevalence in older adults. The syndrome is common in patients with hypertension, obesity, valvular heart disease, diabetes and hypertrophic cardiomyopathy but could also occur in a variety of other clinical disorders such as tachycardia and ischemia. The key pathophysiologic mechanisms include increased myocardial stiffness and delayed left ventricular 

therapy

relaxation. Delayed relaxation causes diastolic abnormalities through inducing abnormal early filling, and in the presence of increased stiffness elevates LV filling pressure and pulmonary pressure more so during exercise leading to diastolic dysfunction. Increased myocardial stiffness increases left atrial pressure and size leading to atrial fibrillation and decreased cardiac output, reduced exercise tolerance and ultimately DHF. Typical signs and symptoms of DHF include exertional dyspnea, fatigue, orthopnea, paroxysmal nocturnal dyspnea, peripheral edema, and exercise intolerance. Diagnosis requires the presence of HF signs and symptoms determined through the assessment of patients' clinical history, physical assessment and electrocardiogram. If at least one of the initial findings is abnormal, clinical evaluation of serum natriuretic peptides should be considered to select patients for echocardiography to assess the presence of normal or mildly reduced left ventricular ejection fraction $(>40 \%)$ and the evidence of structural heart disease or diastolic dysfunction. Although DHF has no specific therapy, its clinical management adopts therapies validated for systolic heart failure. Medical therapy has proved beneficial in the relief of symptoms but its efficacy on reducing hospitalization and mortality rates remains unclear. Exercise therapy improves functional capacity and quality of life, and its inclusion in standard medical therapy is could be safe, feasible and efficacious.

\section{References}

1. Bonow RO, Udelson JE (1992) Left ventricular diastolic dysfunction as a cause of congestive heart failure: mechanisms and management. Ann Intern Med 117: 502-510. [Crossref]

2. Cregler LL, Georgiou D, Sosa I (1991) Left ventricular diastolic dysfunction in patients with congestive heart failure. J Natl Med Assoc 83: 49-52. [Crossref]

3. Lloyd-Jones D, Adams R, Carnethon M, De Simone G, Ferguson TB, Flegal K, Ford E, Furie K, Go A, Greenlund K, Haase N. Heart disease and stroke statistics-2009 update. A report from the American Heart Association Statistics Committee and Stroke Statistics Subcommittee. Circ 119: e21-e181. [Crossref]

4. Thomas MD, Fox KF, Coats AJ, Sutton GC (2004) The epidemiological enigma of heart failure with preserved systolic function. Eur J Heart Fail 6: 125-136. [Crossref]

5. Aronow WS (2006) Epidemiology, pathophysiology, prognosis, and treatment of systolic and diastolic heart failure. Cardiology in review 14: 108-124. [Crossref]

6. Redfield MM, Jacobsen SJ, Burnett Jr JC, Mahoney DW, Bailey KR, et al. (2003) Burden of systolic and diastolic ventricular dysfunction in the community: appreciating the scope of the heart failure epidemic. Jama 289: 194-202. [Crossref]

7. Mandinov L, Eberli FR, Seiler C, Hess OM (2000) Diastolic heart failure. Cardiovasc Res 45: 813-825. [Crossref]

8. Katz AM, Zile MR (2006) New molecular mechanism in diastolic heart failure. Circ 113: 1922-1925. [Crossref]

9. Fishberg, A. M. (1937). Heart Failure. Philadelphia, Pa: Lea \& Febiger.

10. Zile MR, Baicu CF, Gaasch WH (2004) Diastolic heart failure: abnormalities in active relaxation and passive stiffness of the left ventricle. $N$ Engl J Med 350: 1953-1959. [Crossref]

11. Aurigemma GP, Zile MR, Gaasch WH (2006) Contractile behavior of the left ventricle in diastolic heart failure: with emphasis on regional systolic function. Circ 113: 296304. [Crossref]

12. Ferreira RG, Swaminathan M (2013) Quantitative and Semiquantitative Echocardiography: Ventricular and Valvular Physiology. In Perioperative Transesophageal Echocardiography 90-106.

13. Sidebotham D, Grice IJ (2007) Physiology and pathophysiology. In Cardiothoracic Critical, 3-27.

14. Zile MR, Brutsaert DL (2002) New concepts in diastolic dysfunction and diastolic heart failure: Part I: diagnosis, prognosis, and measurements of diastolic function. Circ 105: 1387-1393. [Crossref]

15. Lewis T. (1933). Diseases of the heart. London, UK: MacMillan; 1933.

16. Braunwald, E.(1980). Clinical manifestations of heart failure. In Braunwald E, editor. Heart disease: a textbook of cardiovascular medicine. Philadelphia: WB Saunders.
17. Brutsaert DL, Sys SU, Gillebert TC (1993) Diastolic failure: pathophysiology and therapeutic implications. J Am Coll Cardiol 22: 318-325. [Crossref]

18. Paulus WJ, Tschöpe C, Sanderson JE, Rusconi C, Flachskampf FA, et al. (2007) How to diagnose diastolic heart failure: a consensus statement on the diagnosis of heart failure with normal left ventricular ejection fraction by the Heart Failure and Echocardiography Associations of the European Society of Cardiology. Eur Heart $J$ 28: 2539-2550. [Crossref]

19. McMurray JJ, Adamopoulos S, Anker SD, Auricchio A, Böhm M, et al. (2012) ESC Guidelines for the diagnosis and treatment of acute and chronic heart failure 2012: The Task Force for the Diagnosis and Treatment of Acute and Chronic Heart Failure 2012 of the European Society of Cardiology. Developed in collaboration with the Heart Failure Association (HFA) of the ESC. Eur J Heart Fail 14: 803-869. [Crossref]

20. Ponikowski P, Voors AA, Anker SD, Bueno H, Cleland JG, et al. (2016) 2016 ESC Guidelines for the diagnosis and treatment of acute and chronic heart failure: The Task Force for the diagnosis and treatment of acute and chronic heart failure of the European Society of Cardiology (ESC) Developed with the special contribution of the Heart Failure Association (HFA) of the ESC. Eur Heart J 37: 2129-2200. [Crossref]

21. The Criteria Committee of the New York Heart Association. (1994). Nomenclature and criteria for diagnosis of diseases of the heart and great vessels (9th ED.) Boston, Ma: Little \& Brown

22. Roger VL (2013) Epidemiology of heart failure. Circ Res 113: 646-659. [Crossref]

23. Ziaeian B, Fonarow GC (2016) Epidemiology and aetiology of heart failure. Nat Rev Cardiol 13: 368-378. [Crossref]

24. Van Riet EE, Hoes AW, Wagenaar KP, Limburg A, Landman MA, et al. (2016) Epidemiology of heart failure: the prevalence of heart failure and ventricular dysfunction in older adults over time. A systematic review. Eur J Heart Fail 18: 242252. [Crossref]

25. Kitzman DW, Gardin JM, Gottdiener JS, Arnold A, Boineau R, et al. (2001) Importance of heart failure with preserved systolic function in patients $\geq 65$ years of age. $A m J$ Cardiol 87: 413-419. [Crossref]

26. Gottdiener JS, Arnold AM, Aurigemma GP, Polak JF, Tracy RP, et al. (2000) Predictors of congestive heart failure in the elderly: the Cardiovascular Health Study. $J$ Am Coll Cardiol 35: 1628-1637. [Crossref]

27. Aronow WS (2006) Epidemiology, pathophysiology, prognosis, and treatment of systolic and diastolic heart failure. Cardiology in review 14: 08-124. [Crossref]

28. Vasan RS, Larson MG, Benjamin EJ, Evans JC, Reiss CK, et al (1999) Congestive heart failure in subjects with normal versus reduced left ventricular ejection fraction: prevalence and mortality in a population-based cohort. J Am Coll Cardiol 33: 1948 1955. [Crossref]

29. McKee PA, Castelli WP, McNamara PM, Kannel WB (1971) The natural history of congestive heart failure: the Framingham study. $N$ Engl $J$ Med 285: 1441-1446. [Crossref]

30. Ho KK, Pinsky JL, Kannel WB, Levy D (1993) The epidemiology of heart failure: the Framingham Study. J Am Coll Cardiol 22: A6-A13. [Crossref]

31. McMurray J, Östergren J, Pfeffer M, Swedberg K, Granger C,et al. (2003) Clinica features and contemporary management of patients with low and preserved ejection fraction heart failure: baseline characteristics of patients in the Candesartan in Heart failure-Assessment of Reduction in Mortality and morbidity (CHARM) programme. Eur J Heart Fail 5: 261-270. [Crossref]

32. Carson P, Massie BM, McKelvie R, Mcmurray J, Komajda M, et al. (2005) The irbesartan in heart failure with preserved systolic function (I-PRESERVE) trial: rationale and design. Journal of cardiac failure 11: 576-585. [Crossref]

33. Hogg K, Swedberg K, McMurray J (2004) Heart failure with preserved left ventricular systolic function: epidemiology, clinical characteristics, and prognosis. $\mathrm{J} \mathrm{Am} \mathrm{Coll}$ Cardiol 43: 317-327. [Crossref]

34. Kristensen SL, Køber L, Jhund PS, Solomon SD, Kjekshus J, et al. (2015) International geographic variation in event rates in trials of heart failure with preserved and reduced ejection fraction. Circ 131: 43-53. [Crossref]

35. Andersson C, Vasan RS (2014) Epidemiology of heart failure with preserved ejection fraction. Heart failure clinics 10: 377-388. [Crossref]

36. Owan TE, Hodge DO, Herges RM, Jacobsen SJ, Roger VL, et al. (2006) Trends in prevalence and outcome of heart failure with preserved ejection fraction. $N$ Engl J Med 355: 251-259. [Crossref] 
37. Gerber Y, Weston SA, Redfield MM, Chamberlain AM, Manemann SM, et al. (2010) A contemporary appraisal of the heart failure epidemic in Olmsted County, Minnesota, 2000 to 2010. JAMA internal medicine 175: 996-1004. [Crossref]

38. Steinberg BA, Zhao X, Heidenreich PA, Peterson ED, Bhatt DL, et al. (2012) Trends in patients hospitalized with heart failure and preserved left ventricular ejection fractionprevalence, therapies, and outcomes. Circ: CIRCULATIONAHA-111. [Crossref]

39. Cheng RK, Cox M, Neely ML, Heidenreich PA, Bhatt DL, et al. (2014) Outcomes in patients with heart failure with preserved, borderline, and reduced ejection fraction in the Medicare population. Am Heart J 168: 721-730. [Crossref]

40. Kitzma DW (2002) Diastolic heart failure in the elderly. Heart Failure Reviews 7: 1727. [Crossref]

41. Ahmed A, Aronow WS, Fleg JL (206) Higher New York Heart Association classes and increased mortality and hospitalization in patients with heart failure and preserved left ventricular function. Am Heart J 151: 444-450. [Crossref]

42. Tarantini L, Faggiano P, Senni M, Lucci D, Bertoli D, et al. (2002) Clinical features and prognosis associated with a preserved left ventricular systolic function in a large cohort of congestive heart failure outpatients managed by cardiologists. Data from the Italian Network on Congestive Heart Failure. Italian heart journal 3: 656-664. [Crossref]

43. Taffet GE, Teasdale TA, Bleyer AJ, Kutka NJ, Luchi RJ (1992) Survival of elderly men with congestive heart failure. Age and ageing 21: 49-55. [Crossref]

44. Ahmed A (2005) Association of diastolic dysfunction and outcomes in ambulatory older adults with chronic heart failure. The Journals of Gerontology Series A: Biological Sciences and Medical Sciences, 60: 1339-1344. [Crossref]

45. Ahmed A, Roseman JM, Duxbury AS, Allman RM, DeLong JF (2002) Correlates and outcomes of preserved left ventricular systolic function among older adults hospitalized with heart failure. Am Heart $J$ 144: 365-372. [Crossref]

46. Chatterjee K, Massie B (2007) Systolic and diastolic heart failure: differences and similarities. Journal of cardiac failure 13: 569-576. [Crossref]

47. Borlaug BA, Redfield MM (2011) Diastolic and systolic heart failure are distinct phenotypes within the heart failure spectrumresponse to borlaug and redfield. Circ 123: 2006-2014. [Crossref]

48. De Keulenaer GW, Brutsaert DL (2011) Systolic and Diastolic Heart Failure Are Overlapping Phenotypes Within the Heart Failure SpectrumResponse to De Keulenaer and Brutsaert. Circ 123: 1996-2005. [Crossref]

49. Gary R, Davis L (2008) Diastolic heart failure. Heart \& Lung: The Journal of Acute and Critical Care, 37: 405-416. Crossref

50. Lloyd-Jones DM, Larson MG, Leip EP, Beiser A, D'agostino RB, et al. (2002) Lifetime risk for developing congestive heart failure: the Framingham Heart Study. Circ 106: 3068-3072. [Crossref]

51. Bhatia RS, Tu JV, Lee DS, Austin PC, Fang J, et al. (2006) Outcome of heart failure with preserved ejection fraction in a population-based study. $N$ Engl J Med 355: 260269. [Crossref]

52. East MA, Peterson ED, Shaw LK, Gattis WA, O'Connor CM (2004) Racial differences in the outcomes of patients with diastolic heart failure. Am Heart $J$ 148: 151-156. [Crossref]

53. Aurigemma GP, Gaasch WH (2004) Diastolic heart failure. N Engl J Med 351: 1097 1105. [Crossref]

54. Borlaug BA, Paulus WJ (2010) Heart failure with preserved ejection fraction: pathophysiology, diagnosis, and treatment. Eur Heart J 32: 670-679. [Crossref]

55. Kitzman DW, Gardin JM, Gottdiener JS, Arnold A, Boineau R, et al. (2001) Importance of heart failure with preserved systolic function in patients $\geq 65$ years of age. $\mathrm{Am} J$ Cardiol 87: 413-419. [Crossref]

56. Devereux RB, Pickering TG, Harshfield GA, Kleinert HD, Denby L, et al. (1983) Left ventricular hypertrophy in patients with hypertension: importance of blood pressure response to regularly recurring stress. Circ 68: 470-476. [Crossref]

57. Gradman AH, Pangan P, Germain M (1989) Lack of correlation between clinic and 24 hour ambulatory blood pressure in subjects participating in a therapeutic drug trial. Journal of clinical epidemiology 42: 1049-1054. [Crossref]

58. Gradman AH, Alfayoumi F (2006) From left ventricular hypertrophy to congestive heart failure: management of hypertensive heart disease. Prog Cardiovasc Dis 48: 326341. [Crossref]

59. Lamb HJ, Beyerbacht HP, Van Der Laarse A, Stoel BC, Doornbos J, et al. (1999) Diastolic dysfunction in hypertensive heart disease is associated with altered myocardial metabolism. Circ 99: 2261-2267. [Crossref]
60. Zile MR, Baicu CF, Bonnema DD (2005) Diastolic heart failure: definitions and terminology Prog Cardiovasc Dis 47: 307-313. [Crossref]

61. Leite-Moreira AF, Correia-Pinto J, Gillebert TC (1999) Afterload induced changes in myocardial relaxation: a mechanism for diastolic dysfunction. Cardiovascular research 43: 344-353. [Crossref]

62. Sadoshima JI, Xu Y, Slayter HS, Izumo S (1993) Autocrine release of angiotensin II mediates stretch-induced hypertrophy of cardiac myocytes in vitro. Cell 75: 977-984. [Crossref]

63. Van Heugten HA, De Jonge HW, Goedbloed MA, Bezstarosti K, Sharma HS, et al. (1995) Intracellular signaling and genetic reprogramming during development of hypertrophy in cultured cardiomyocytes. InHeart Hypertrophy and Failure 1995 (pp. 79-92). Springer, Boston, MA. [Crossref]

64. Hardin NJ (1996) The myocardial and vascular pathology of diabetic cardiomyopathy Coronary artery disease 7: 99-108. [Crossref]

65. Iribarren C, Karter AJ, Go AS, Ferrara A, Liu JY, et al. (2001) Glycemic control and heart failure among adult patients with diabetes. Circ 103: 2668-2673. [Crossref]

66. Peterson LR, Waggoner AD, Schechtman KB, Meyer T, Gropler RJ, et al. (2004) Alterations in left ventricular structure and function in young healthy obese women: assessment by echocardiography and tissue Doppler imaging. J Am Coll Cardiol 43 : 1399-1404. [Crossref]

67. Boyer JK, Thanigaraj S, Schechtman KB, Pérez JE (2004) Prevalence of ventricular diastolic dysfunction in asymptomatic, normotensive patients with diabetes mellitus. Am J Cardiol 93: 870-875. [Crossref]

68. From AM, Scott CG, Chen HH (2010) The development of heart failure in patients with diabetes mellitus and pre-clinical diastolic dysfunction: a population-based study. $J \mathrm{Am}$ Coll Cardiol 55: 300-305. [Crossref]

69. Khan KA, Jalal S, Baba RM, Jan V, Rather H, et al. (2006) Prevalence of diastolic dysfunction in normotensive asymptomatic patients with well $\square$ controlled type2 diabetes mellitus. Journal of Chinese Clinical Medicine. [Crossref]

70. Zabalgoitia M, Ismaeil MF, Anderson L, Maklady FA (2001) Prevalence of diastolic dysfunction in normotensive, asymptomatic patients with well-controlled type 2 diabetes mellitus. Am J Cardiol 87: 320-323. [Crossref]

71. Liu JE, Robbins DC, Palmieri V, Bella JN, Roman MJ, et al. (2003) Association of albuminuria with systolic and diastolic left ventricular dysfunction in type 2 diabetes: the Strong Heart Study. J Am Coll Cardiol 41: 2022-2028. [Crossref]

72. Iribarren C, Karter AJ, Go AS, Ferrara A, Liu JY, et al. (2001) Glycemic control and heart failure among adult patients with diabetes. Circ 103: 2668-2673. [Crossref]

73. Lakatta EG (2002) Age-associated cardiovascular changes in health: impact on cardiovascular disease in older persons. Heart Failure Reviews 7: 29-49. [Crossref]

74. Braunstein JB, Anderson GF, Gerstenblith G, Weller W, Niefeld M, et al. (2003) Noncardiac comorbidity increases preven hospitalizations and mortality among Medicare beneficiaries with chronic heart failure. J Am Coll Cardiol 42: 1226-1233. [Crossref]

75. Lien CT, Gillespie ND, Struthers AD, McMurdo ME (2002) Heart failure in frail elderly patients: diagnostic difficulties, co-morbidities, polypharmacy and treatment dilemmas. Eur J Heart Fail 4: 91-98. [Crossref]

76. Wells RG (2008) The role of matrix stiffness in regulating cell behavior. Hepatology 47: 1394-1400. [Crossref]

77. Ahmed SH, Clark LL, Pennington WR, Webb CS, Bonnema DD, et al. (2006) Matrix metalloproteinases/tissue inhibitors of metalloproteinases: relationship between changes in proteolytic determinants of matrix composition and structural, functional, and clinical manifestations of hypertensive heart disease. Circ 113: 2089-2096. [Crossref]

78. Heymans S, Schroen B, Vermeersch P, Milting H, Gao F, et al. (2005) Increased cardiac expression of tissue inhibitor of metalloproteinase- 1 and tissue inhibito of metalloproteinase- 2 is related to cardiac fibrosis and dysfunction in the chronic pressure-overloaded human heart. Circ 112: 1136-1144. [Crossref]

79. Kramer F, Sandner P, Klein M, Krahn T (2008) Plasma concentrations of matrix metalloproteinase-2, tissue inhibitor of metalloproteinase-1 and osteopontin reflect severity of heart failure in DOCA-salt hypertensive rat. Biomarkers 13: 270-281. [Crossref]

80. Spinale FG, Coker ML, Heung LJ, Bond BR, Gunasinghe HR, et al. (2000) A matrix metalloproteinase induction/activation system exists in the human left ventricular myocardium and is upregulated in heart failure. Circ 102: 1944-1949. [Crossref] 

therapy

81. Van Heerebeek L, Borbély A, Niessen HW, Bronzwaer JG, van der Velden J, et al. (2006) Myocardial structure and function differ in systolic and diastolic heart failure. Circ 113: 1966-1973. [Crossref]

82. Polyakova V, Hein S, Kostin S, Ziegelhoeffer T, Schaper J (2004) Matrix metalloproteinases and their tissue inhibitors in pressure-overloaded human myocardium during heart failure progression. J Am Coll Cardiol 44: 1609-1618. [Crossref]

83. Borbély A, van der Velden J, Papp Z, Bronzwaer JG, Edes I, et al. (2005) Cardiomyocyte stiffness in diastolic heart failure. Circ 111: 774-781. [Crossref]

84. Van Heerebeek L, Hamdani N, Handoko ML, Falcao-Pires I, Musters RJ, et al. (2008) Diastolic stiffness of the failing diabetic heart: importance of fibrosis, advanced glycation end products, and myocyte resting tension. Circ 117: 43-51. [Crossref]

85. Chaturvedi RR, Herron T, Simmons R, Shore D, Kumar P, et al. (2010) Passive stiffness of myocardium from congenital heart disease and implications for diastole. Circ 121: 979-988. [Crossref]

86. Bang ML, Centner T, Fornoff F, Geach AJ, Gotthardt M, et al. (2001) The complete gene sequence of titin, expression of an unusual $\approx 700-\mathrm{kDa}$ titin isoform, and its interaction with obscurin identify a novel Z-line to I-band linking system. Circ Res 89: 1065-1072. [Crossref]

87. Neagoe C, Opitz CA, Makarenko I, Linke WA (2003) Gigantic variety: expression patterns of titin isoforms in striated muscles and consequences for myofibrillar passive stiffness. Journal of Muscle Research \& Cell Motility 24: 175-189. [Crossref]

88. Nagueh SF, Shah G, Wu Y, Torre-Amione G, King NM, et al. (2004) Altered titin expression, myocardial stiffness, and left ventricular function in patients with dilated cardiomyopathy. Circ 110: 155-162. [Crossref]

89. Makarenko I, Opitz CA, Leake MC, Neagoe C, Kulke M, et al. (2004) Passive stiffness changes caused by upregulation of compliant titin isoforms in human dilated cardiomyopathy hearts. Circ Res 95: 708-716. [Crossref]

90. Krüger M, Kötter S, Grützner A, Lang P, Andresen C, Redfield MM, Butt E, Dos Remedios CG, Linke WA. Protein kinase G modulates human myocardial passive stiffness by phosphorylation of the titin springs. Circ Res 104: 87-94. [Crossref]

91. Hudson BD, Hidalgo CG, Bogomolovas J, Zhu Y, Anderson B, et al. (2010) PKC Phosphorylation of Titin's PEVK Element--A Novel and Conserved Pathway for Modulating Myocardial Stiffness. Biophysical Journal 98: 756a. [Crossref]

92. Lam CS, Roger VL, Rodeheffer RJ, Borlaug BA, Enders FT, et al. (2009) Pulmonary hypertension in heart failure with preserved ejection fraction: a community-based study. J Am Coll Cardiol 53: 1119-1126. [Crossref]

93. Borlaug BA, Redfield MM, Melenovsky V, Kane GC, Karon BL, et al. (2013) Jacobsen SJ, Rodeheffer RJ. Longitudinal changes in left ventricular stiffness: a communitybased study. Circ-Heart Fail 6: 944-952. [Crossref]

94. Solomon SD, Janardhanan R, Verma A, Bourgoun M, Daley WL, et al. (2007) Effect of angiotensin receptor blockade and antihypertensive drugs on diastolic function in patients with hypertension and diastolic dysfunction: a randomised trial. The Lancet 369: 2079-2087. [Crossref]

95. Owan TE, Hodge DO, Herges RM, Jacobsen SJ, Roger VL, et al. (2006) Trends in prevalence and outcome of heart failure with preserved ejection fraction. $N$ Engl J Med 355: 251-259. [Crossref]

96. Ramirez-Correa GA, Murphy AM (2007) Is Phospholamban or Troponin I the "prima Donna" in $\beta$-adrenergic Induced Lusitropy? Circ Res 101: 326-327. [Crossref]

97. Paulus WJ, Vantrimpont PJ, Shah AM (1994) Acute effects of nitric oxide on left ventricular relaxation and diastolic distensibility in humans. Assessment by bicoronary sodium nitroprusside infusion. Circ 89: 2070-2078. [Crossref]

98. Smith CS, Bottomley PA, Schulman SP, Gerstenblith G, Weiss RG (2006) Altered creatine kinase adenosine triphosphate kinetics in failing hypertrophied human myocardium. Circ 114: 1151-1158. [Crossref]

99. Phan TT, Abozguia K, Shivu GN, Mahadevan G, Ahmed I, et al. (2009) Heart failure with preserved ejection fraction is characterized by dynamic impairment of active relaxation and contraction of the left ventricle on exercise and associated with myocardial energy deficiency. J Am Coll Cardiol 54: 402-409. [Crossref]

100. Rich MW (1997) Congestive heart failure in older adults: Epidemiology, Pathophysiology, and Etiology of Congestive Heart Failure in Older Adults. J Am Geriatr Soc 45: 968-974. [Crossref]

101. Paul S (2003) Diastolic dysfunction. Critical Care Nursing Clinics of North America, 15: 495-500. [Crossref]
102. Beattie S (2000) Heart failure with preserved LV function: pathophysiology, clinical presentation, treatment, and nursing implications. Journal of Cardiovascular Nursing 14: 24-37. [Crossref]

103. Kitzman DW (2005) Exercise intolerance. Prog Cardiovasc Dis 47: 367-379. [Crossref]

104. Little WC, Kitzman DW, Cheng CP (2000) Diastolic dysfunction as a cause of exercise intolerance. Heart failure reviews 5: 301-306[Crossref]

105. Gaasch WH, Zile MR (2004) Left ventricular diastolic dysfunction and diastolic heart failure. Annu. Rev. Med 55: 373-94. [Crossref]

106. Vasan RS, Levy D (2000) Defining diastolic heart failure: a call for standardized diagnostic criteria. Circ 101: 2118-2121. [Crossref]

107. Yancy CW, Jessup M, Bozkurt B, Butler J, Casey DE, et al. (2013) 2013 ACCF/ AHA guideline for the management of heart failure: a report of the American College of Cardiology Foundation/American Heart Association Task Force on Practice Guidelines. J Am Coll Cardiol 62: e147-e239. [Crossref]

108. Davie AP, Francis CM, Caruana L, Sutherland GR, McMurray JJ (1997) Assessing diagnosis in heart failure: which features are any use?. QJM 90: 335-339. [Crossref]

109. Mant J, Doust J, Roalfe A, Barton P, Cowie MR, et al.(2009) Systematic review and individual patient data meta-analysis of diagnosis of heart failure, with modelling of implications of different diagnostic strategies in primary care. [Crossref]

110. Oudejans I, Mosterd A, Bloemen JA, Valk MJ, van Velzen E, et al, (2011) Clinical evaluation of geriatric outpatients with suspected heart failure: value of symptoms, signs, and additional tests. Eur J Heart Fail 13: 518-527. [Crossref]

111. Fonseca C (2006) Diagnosis of heart failure in primary care. Heart Failure Reviews 11: 95-107. [Crossref]

112. Rutten FH, Moons KG, Cramer MJ, Grobbee DE, Zuithoff NP, et al. (2005) Recognising heart failure in elderly patients with $\mathrm{s}$ chronic obstructive pulmonary disease in primary care: cross sectional diagnostic study. Bmj 331: 1379. [Crossref]

113. Hawkins NM, Petrie MC, Jhund PS, Chalmers GW, Dunn FG, et al. (2009) Heart failure and chronic obstructive pulmonary disease: diagnostic pitfalls and epidemiology. Eur J Heart Fail 11: 130-139. [Crossref]

114. Daniels LB, Clopton P, Bhalla V, Krishnaswamy P, Nowak RM, et al. (2006) How obesity affects the cut-points for B-type natriuretic peptide in the diagnosis of acute heart failure: results from the Breathing Not Properly Multinational Study. Am Heart $J$ 151: 999-1005. [Crossref]

115. Wong CM, Hawkins NM, Jhund PS, MacDonald MR, Solomon SD, et al. (2013) Clinical characteristics and outcomes of young and very young adults with heart failure: the CHARM programme (Candesartan in Heart Failure Assessment of Reduction in Mortality and Morbidity). J Am Coll Cardiol 62: 1845-1854. [Crossref]

116. Wong CM, Hawkins NM, Petrie MC, Jhund PS, Gardner RS, et al. (2014) Heart failure in younger patients: the Meta-analysis Global Group in Chronic Heart Failure (MAGGIC). Eur Heart J 35: 2714-2721. [Crossref]

117. Van Riet EE, Hoes AW, Limburg A, Landman MA, van der Hoeven H, et al. (2014) Prevalence of unrecognized heart failure in older persons with shortness of breath on exertion. Eur J Heart Fail 16: 772-777. [Crossref]

118. Kelder JC, Cramer MJ, van Wijngaarden J, van Tooren R, Mosterd A, et al. (2011) The Diagnostic Value of Physical Examination and Additional Testing in Primary Care Patients With Suspected Heart FailureClinical Perspective. Circ 124: 28652873. [Crossref]

119. Davie AP, Francis CM, Love MP, Caruana L, Starkey IR, et al. (1996) Value of the electrocardiogram in identifying heart failure due to left ventricular systolic dysfunction. BMJ 312: 222.

120. Thomas JT, Kelly RF, Thomas SJ, Stamos TD, Albasha K, et al. (2002) Utility of history, physical examination, electrocardiogram, and chest radiograph for differentiating normal from decreased systolic function in patients with heart failure. American journal of medicine 112: 437-445. [Crossref]

121. Roberts E, Ludman AJ, Dworzynski K, Al-Mohammad A, Cowie MR, et al, (2015) The diagnostic accuracy of the natriuretic peptides in heart failure: systematic review and diagnostic meta-analysis in the acute care setting. Bmj 350: h910. [Crossref]

122. Zaphiriou A, Robb S, Murray-Thomas T, Mendez G, Fox K, et al. (2005) The diagnostic accuracy of plasma BNP and NTproBNP in patients referred from primary care with suspected heart failure: results of the UK natriuretic peptide study. Eur J Heart Fail 7: 537-541. [Crossref] 
123. Fuat A, Murphy JJ, Hungin AP, Curry J, Mehrzad AA, et al. (2006) The diagnostic accuracy and utility of a B-type natriuretic peptide test in a community population of patients with suspected heart failure. Br J Gen Pract 56: 327-333. [Crossref]

124. Cowie MR, Struthers AD, Wood DA, Coats AJ, Thompson SG, et al. (1997) Value of natriuretic peptides in assessment of patients with possible new heart failure in primary care. The Lancet 350: 1349-1353. [Crossref]

125. Krishnaswamy P, Lubien E, Clopton P (2002) Utility of B-natriuretic peptide levels in identifying patients with left ventricular systolic or diastolic dysfunction. $A C C$ Current Journal Review 2: 274-279. [Crossref]

126. Kelder JC, Cramer MJ, Verweij WM, Grobbee DE, Hoes AW (2011) Clinical utility of three B-type natriuretic peptide assays for the initial diagnostic assessment of new slow-onset heart failure. Journal of cardiac failure 17: 729-734. [Crossref]

127. Madamanchi C, Alhosaini H, Sumida A, Runge MS (2014) Obesity and natriuretic peptides, BNP and NT-proBNP: mechanisms and diagnostic implications for heart failure. International journal of cardiology 176: 611-617. [Crossref]

128. Kirkpatrick JN, Vannan MA, Narula J, Lang RM (2007) Echocardiography in heart failure: applications, utility, and new horizons. J Am Coll Cardiol 50: 381-396. [Crossref]

129. Nagueh SF, Bhatt R, Vivo RP, Krim SR, Sarvari SI, et al. (2011) Echocardiographic evaluation of hemodynamics in patients with decompensated systolic heart failure. Circulation: Cardiovascular Imaging 4: 220-227. [Crossref]

130. Lang RM, Badano LP, Mor-Avi V, Afilalo J, Armstrong A, et al. (2015) Recommendations for cardiac chamber quantification by echocardiography in adults: an update from the American Society of Echocardiography and the European Association of Cardiovascular Imaging. Eur Heart J Cardiovasc Imaging 16: 233271. [Crossref]

131. Nagueh SF, Smiseth OA, Appleton CP, Byrd BF, Dokainish H, et al. (2016) Recommendations for the evaluation of left ventricular diastolic function by echocardiography: an update from the American Society of Echocardiography and the European Association of Cardiovascular Imaging. "Eur J Echocardiogr 17: 13211360. [Crossref]

132. Edelmann F, Wachter R, Schmidt AG, Kraigher-Krainer E, Colantonio C, et al. (2013) Effect of spironolactone on diastolic function and exercise capacity in patients with heart failure with preserved ejection fraction: the Aldo-DHF randomized controlled trial. Jama 309: 781-791. [Crossref]

133. Kim YH, Kim SH, Lim SY, Cho GY, Baik IK, et al. (2012) Relationship between depression and subclinical left ventricular changes in the general population. Heart 98: 1378-1383. [Crossref]

134. Ohtani T, Mohammed SF, Yamamoto K, Dunlay SM, Weston SA, et al. (2012) Diastolic stiffness as assessed by diastolic wall strain is associated with adverse remodelling and poor outcomes in heart failure with preserved ejection fraction. Eur Heart J 33: 1742-1749. [Crossref]

135. Palevo G, Keteyian SJ, Kang M, Caputo JL (2009) Resistance exercise training improves heart function and physical fitness in s patients with heart failure. Journal of cardiopulmonary rehabilitation and prevention 29: 294-298. [Crossref]

136. Braunschweig F, Linde C, Adamson PB, Magalski A, Erdmann E, et al. (2009) Continuous central haemodynamic measurements during the six-minute walk tes and daily life in patients with chronic heart failure. Eur J Heart Fail 11: 594-601. [Crossref]

137. Powell LH, Calvin Jr JE, de Leon CF, Richardson D, Grady KL, et al. (2008The heart failure adherence and retention trial (HART): Design and rationale. Am Heart $J 156$ : 452-460. [Crossref]

138. Gary R, Lee SY (2007) Physical function and quality of life in older women with diastolic heart failure: effects of a progressive walking program on sleep patterns. Progress in cardiovascular nursing 22: 72-80. [Crossref]

139. Klecha A, Kawecka-Jaszcz K, Bacior B, Kubinyi A, Pasowicz M, et al. (2007) Physical training in patients with chronic heart failure of ischemic origin: effect on exercise capacity and left ventricular remodeling. Eur J Cardiovasc Prev Rehabil 14: 85-91. [Crossref]

140. Rebecca G (2006) Exercise self-efficacy in older women with diastolic heart failure: results of a walking program and education intervention. Journal of gerontological nursing 32: 31. [Crossref]

141. Giannuzzi P, Temporelli PL, Corrà U, Tavazzi L (2003) Antiremodeling effect of long-term exercise training in patients with $\mathrm{s}$ chronic heart failure: results of the Exercise in Left Ventricular Dysfunction and Chronic Heart Failure (ELVD-CHF) Trial. Circ 108: 554-559. [Crossref]
142. Silva MS, Bocchi EA, Guimarães GV, Padovani CR, Silva MH, et al. (2002) Benefits of exercise training in the treatment of heart failure: study with a control group. Arquivos brasileiros de cardiologia 79: 357-362. [Crossref]

143. Ommen SR, Nishimura R, Appleton CP, Miller FA, Oh JK, et al. (2000) Clinical utility of Doppler echocardiography and tissue Doppler imaging in the estimation of left ventricular filling pressures: a comparative simultaneous Doppler-catheterization study. Circ 102: 1788-1794. [Crossref]

144. Dokainish H, Zoghbi WA, Lakkis NM, Al-Bakshy F, Dhir M, et al. (2004) Optima noninvasive assessment of left ventricular filling pressures: a comparison of tissue Doppler echocardiography and B-type natriuretic peptide in patients with pulmonary artery catheters. Circ 109: 2432-2439. [Crossref]

145. Hadano Y, Murata K, Liu J, Oyama R, Harada N, et al. (2005) Can transthoracic Doppler echocardiography predict the discrepancy between left ventricular enddiastolic pressure and mean pulmonary capillary wedge pressure in patients with heart failure?. Circ 69: 432-438. [Crossref]

146. Kasner M, Westermann D, Steendijk P, Gaub R, Wilkenshoff U, et al. (2007) Clinical Perspective. Circ 116: 637-647. [Crossref]

147. Wang J, Khoury DS, Thohan V, Torre-Amione G, Nagueh SF (2007) Global diastolic strain rate for the assessment of left ventricular relaxation and filling pressures. Circ 115: 1376-1383. [Crossref]

148. Dini FL, Ballo P, Badano L, Barbier P, Chella P, et al. (2010) Validation of an echoDoppler decision model to predict left ventricular filling pressure in patients with heart failure independently of ejection fraction. Eur J Echocardiogr 11: 703-710. [Crossref]

149. Dokainish H, Nguyen J, Sengupta R, Pillai M, Alam M, et a;l. (2010) New, simple echocardiographic indexes for the estimation of filling pressure in patients with cardiac disease and preserved left ventricular ejection fraction. Echocardiography 27: 946-953. [Crossref]

150. Kasner M, Gaub R, Sinning D, Westermann D, Steendijk P, Hoffmann W, Schultheiss HP, Tschöpe C. Global strain rate imaging for the estimation of diastolic function in HFNEF compared with pressure-volume loop analysis. "Eur J Echocardiogr 11 743-751. [Crossref]

151. Penicka M, Bartunek J, Trakalova H, Hrabakova H, Maruskova M, et al. (2010) Heart failure with preserved ejection fraction in outpatients with unexplained dyspnea: a pressure-volume loop analysis. J Am Coll Cardiol 55: 1701-1710. [Crossref]

152. Hsiao SH, Chiou KR, Lin KL, Lin SK, Huang WC, et al. (2011) eft Atria Distensibility and E/e'for Estimating Left Ventricular Filling Pressure in Patients With S Angina. Circ 75: 1942-1950. [Crossref]

153. Previtali M, Chieffo E, Ferrario M, Klersy C (2011) Is mitral E/E' ratio a reliable predictor of left ventricular diastolic pressures in patients without heart failure? European Heart J-Cardiovascular Imaging 13: 588-595. [Crossref]

154. Poorrafsanjani MH, Darabad BR (2014) Evaluate the sensitivity and specificity echocardiography in trans-Doppler and tissue Doppler method in the estimation of left ventricular end-diastolic pressure. Global journal of health science 6: 92 [Crossref]

155. Cameli M, Sparla S, Losito M, Righini FM, Menci D, et al. (2016Correlation of left atrial strain and Doppler measurements with invasive measurement of left ventricular end-diastolic pressure in patients stratified for different values of ejection fraction. Echocardiography 33: 398-405. [Crossref]

156. Andersen OS, Smiseth OA, Dokainish H, Abudiab MM, Schutt RC, Kumar A, Sato K, Harb S, Gude E, Remme EW, Andreassen AK. Estimating left ventricular filling pressure by echocardiography. J Am Coll Cardiol 69: 1937-1948. [Crossref]

157. Ito H, Ishii K, Iwakura K, Nakamura F, Nagano T, et al. (20090 Impact of azelnidipine treatment on left ventricular diastolic performance in patients with hypertension and mild diastolic dysfunction: multi-center study with echocardiography. Hypertension Research 32: 895. [Crossref]

158. Kurioka S, Ose H, Fukuma K, Yoshimoto K (2013) Severity of diabetic retinopathy is associated with left ventricular diastolic dysfunction in patients with type 2 diabetes. Diabetes research and clinical practice 99: 287-291. [Crossref]

159. Sharifov OF, Schiros CG, Aban I, Denney Jr TS, Gupta H (2016) Diagnostic Accuracy of Tissue Doppler Index E/è for Evaluating Left Ventricular Filling Pressure and Diastolic Dysfunction/Heart Failure With Preserved Ejection Fraction: A Systematic Review and Meta-Analysis. J Am Heart Assoc 5: e002530. [Crossref]

160. Gary RA, Sueta CA, Dougherty M, Rosenberg B, Cheek D, et al. (2004) Home-based exercise improves functional performance and quality of life in women with diastolic heart failure. Heart \& Lung: The Journal of Acute and Critical Care 33: 210-218. [Crossref] 

therapy

161. Kitzman DW, Brubaker PH, Morgan TM, Stewart KP, Little WC (2010) Exercise training in older patients with heart failure and preserved ejection fraction: a randomized, controlled, single-blind trial. Circ-Heart Fail 3: 659-667. [Crossref]

162. Edelmann F, Gelbrich G, Düngen HD, Fröhling S, Wachter R, et al. (2011) Exercise training improves exercise capacity and diastolic function in patients with heart failure with preserved ejection fraction: results of the Ex-DHF (Exercise training in Diastolic Heart Failure) pilot study. J Am Coll Cardiol 58: 1780-1791. [Crossref]

163. Smart NA, Haluska B, Jeffriess L, Leung D (2012) Exercise training in heart failure with preserved systolic function: a randomized controlled trial of the effects on cardiac function and functional capacity. Congestive heart failure 18: 295-301. [Crossref]

164. Kitzman DW, Brubaker PH, Herrington DM, Morgan TM, Stewart KP, et al. (2013) Effect of endurance exercise training on endothelial function and arterial stiffness in older patients with heart failure and preserved ejection fraction: a randomized, controlled, single-blind trial. J Am Coll Cardiol 62: 584-592. [Crossref]
165. Pandey A, Parashar A, Kumbhani DJ, Agarwal S, Garg J, et al. (2015) Exercise training in patients with heart failure and preserved ejection fraction: meta-analysis of randomized control trials. Circ-Heart Fail 8: 33-40. [Crossref]

166. Fujimoto N, Prasad A, Hastings JL, Bhella PS, Shibata S, et al. (2012) Cardiovascular effects of 1 year of progressive endurance exercise training in patients with heart failure with preserved ejection fraction. Am Heart J 164: 869-877. [Crossref]

167. Belardinelli R, Georgiou D, Cianci G, Purcaro A (2012) 10-year exercise training in chronic heart failure: a randomized controlled trial. J Am Coll Cardiol 60: 15211528. [Crossref]

168. Korzeniowska-Kubacka I, Bilińska M, Michalak E, Kuśmierczyk-Droszcz B, Dobraszkiewicz-Wasilewska B, et al. (2010) Influence of exercise training on left ventricular diastolic function and its relationship to exercise capacity in patients after myocardial infarction. Cardiology journal 17: 136-142. [Crossref]

Copyright: $(02018$ Albakri A. This is an open-access article distributed under the terms of the Creative Commons Attribution License, which permits unrestricted use, distribution, and reproduction in any medium, provided the original author and source are credited. 